\title{
The Sensitivity of the Regional Coupled Ocean-Atmosphere Simulations over the Intra-Americas Seas to the prescribed bathymetry
}

\author{
Vasubandhu Misra ${ }^{1,2,3}$, A. Mishra ${ }^{1}$, and Haiqin $\mathrm{Li}^{4,5}$
}


24 Key words: Coupled downscaling; Intra-Americas Seas; Warm Pool; Loop Current, SST

25 bias

26 Abstract

27 This study examines the sensitivity of the coupled ocean-atmosphere climate of

28 the Intra-Americas Seas (IAS; which includes the Gulf of Mexico and the Caribbean Sea)

29 and parts of the western tropical and sub-tropical Atlantic Ocean to the prescribed

30 bathymetry in three independent multi-decadal, high-resolution (15 km grid interval),

31 regional coupled ocean-atmosphere model (RCM) integrations centered over the IAS. All

32 of these RCM integrations with different prescribed bathymetries are forced by identical

33 global atmospheric and oceanic reanalysis at the lateral boundaries. It is observed that the

34 model integration with a smoother and coarser bathymetry in the region (RCM-C) results

35 in more widespread sea surface temperature (SST) bias across the IAS. We also note that

36 the bias displayed by the RCM-C simulation is analogous to the bias in the IAS ocean

37 circulation of some Coupled Model Intercomparison Project version 5 (CMIP5) models.

38 The models with an intermediate bathymetry (RCM-I) and finest bathymetry

39 (RCM-F) rectify the bias in ocean transport through the Yucatan Channel relative to

40 RCM-C but display mixed results with respect to SST bias. The RCM-C integration uses

41 a bathymetry with a shallower Yucatan Channel, which tends to produce unrealistically

42 weak flow through the Yucatan Channel and a weak Loop Current. However, the

43 stronger heat transport through the Yucatan Channel in RCM-F results in significant

44 warming of the northwestern tropical Atlantic Ocean and associated weakening of the

45 surface easterly atmospheric winds relative to the other RCM integrations. Due to the

46 weaker surface wind-induced shelf currents, the area comprised of western Gulf of

47 Mexico and southern Caribbean Sea have a severe cold SST bias over the IAS in RCM-F 
48 relative to either RCM-I or RCM-C. RCM-I on the other hand significantly warms the

49 western Gulf of Mexico. RCM-I displays the least SST bias over the IAS and the ocean

50 transport through the Yucatan Channel is most comparable to the ocean reanalysis.

51 We contend that RCM-I produces the most accurate simulation as a result of the

52 coupled response to changes in bathymetry that optimizes the response of the modulation

53 of the surface easterlies, which triggers sufficient ocean eddy activity in the western Gulf

54 of Mexico and energizes the shelf currents. However, the uniform cold SST bias in the

55 regional domain of all three simulations is also associated with a corresponding

56 underestimation of the net heat flux into the ocean. The findings of this study clearly

57 suggest that ameliorations of the SST bias in the IAS have their origins both in the

58 atmospheric and oceanic components of the climate system.

59 


\section{Introduction}

61 The Intra-Americas Seas (IAS), which includes the Gulf of Mexico (GoM) and

62 the Caribbean Sea, is a major source of moisture for continental North America

63 throughout the year (Ruiz-Barradas and Nigam 2005; Mo et al. 2005; Wang et al. 2006;

64 Chan and Misra 2010; Misra et al. 2014). For example, Chang and Oey (2010a) assert

65 that without the effects of the GoM, the U.S. "Corn Belt" region would not likely be so

66 named. Even some of the most severe winter storms that affected the eastern United

67 States originated in the GoM (Bosart and Lin 1984; Businger et al. 1990). Similarly, the

68 ocean heat content in the IAS plays an important role in the intensity changes of several

69 Atlantic tropical cyclones (Shay et al. 2000; Mainelli et al. 2008; Shay 2009; Rappaport

70 et al. 2010). Therefore, the importance of the IAS in regulating the climate and weather

71 over a major part of continental North America cannot be overemphasized.

72 The IAS is also a region that hosts a major fraction of the largest western

73 hemisphere warm pool (Wang and Enfield 2001). This Atlantic Warm Pool (AWP) is

74 objectively defined as the area enclosed by $28.5^{\circ} \mathrm{C}$ isotherm in the IAS region and in the

75 western tropical and subtropical Atlantic Ocean (Wang and Enfield 2001, 2003). The

76 AWP is a seasonal feature that appears in the boreal summer season, which peaks in

77 middle of summer and disappears by late fall or early winter (Lee et al. 2005; Misra et al.

78 2013, 2014). The size of the AWP exhibits distinct interannual (Wang and Enfield 2001;

79 2003; Wang et al. 2006, 2008a) and decadal variability (Wang et al. 2008b; Zhang et al.

80 2012). Diagnostic studies of the surface heat budget from ocean reanalysis and Ocean

81 General Circulation Model (OGCM) simulations suggest that the cloud radiative fluxes 
82 play a dominant role in the seasonal cycle and interannual variability of the AWP (Lee et 83 al. 2007; Misra et al. 2013).

84 In a related study, Clement et al. (2005) showed that ocean dynamics play a very

85 important role in sustaining the warm pool in the western Pacific Ocean. They showed

86 that the ocean dynamics, through poleward Ekman transport with the compensatory

87 underlying Sverdrup dynamics of equatorward geostrophic flow and linked by equatorial

88 upwelling, negate the homogenizing effects of the atmospheric processes to sustain the

89 warm pool in the tropical Pacific. While their study could be generalized for all tropical

90 warm pools, the geography and the bathymetry of the IAS is too different from the

91 tropical Pacific to exactly relate it to the AWP. For example, Liu et al. (2012a) suggested

92 that the dominating terms in the upper ocean heat budget of the GoM are the contrasting

93 warming tendency of the upper ocean heat transport and cooling tendency of the net

94 surface atmospheric fluxes. Nonetheless, the ocean transport of heat into and out of the

95 IAS is fundamental for the regulation of its SST (Jayne and Marotzke 2002; Chang and

96 Oey 2010a, b; Liu et al. 2012b). The Loop Current essentially brings the warm and saline

97 water from the equatorial Atlantic to the GoM (Chang and Oey 2010b). It should be

98 mentioned that the prevailing Loop Current that enters through the Yucatan Channel

99 (YC) and exits through the Florida Straits represents the upper limb of the global

100 thermohaline circulation in the North Atlantic, a major source of the Gulf Stream, and

101 constitutes a major part of the western boundary current in the North Atlantic Subtropical

102 Gyre (Schmitz and Richardson 1991).

103 The purpose of this study is to demonstrate the sensitivity of model simulations of

104 the IAS climate and its variations to changes in the prescribed ocean bathymetry in a 
105 regional coupled ocean-atmosphere model. Three regional model integrations that are

106 identical to each other except for the bathymetry employed are analyzed for their

107 differences in this study. The motivation for this study is presented in the following

108 section, which discusses the bias over the IAS in contemporary global climate models. A

109 brief discussion of the model is provided in Section 3. The experiment design is

110 presented in Section 4. The model simulations are then compared with each other and

111 with observations (where available) and reanalysis that are used in forcing the regional

112 model in the results Section 5. This is followed in Section 6 with a discussion of the

113 lessons learned from the regional model integrations and potential relation to the bias

114 displayed by the global models. The summary and conclusions are presented in Section 7.

117 Several studies have shown that invariably all current and earlier versions of

118 Coupled ocean-atmosphere General Circulation Models (CGCMs) display a very cold

119 bias in the IAS region resulting in much smaller AWPs than are observed (Misra et al.

120 2009; Kozar and Misra 2012; Liu et al. 2012a, 2013). In fact, Kozar and Misra (2012)

121 showed that even the seasonal cycle of the AWP has significant errors in the $20^{\text {th }}$ century

122 simulations of the CMIP5 suite of models. Many of these studies point to erroneous

123 cloud-radiative feedbacks as a potential cause for this rather systematic cold SST bias

124 displayed by general circulation models.

125 A complementary theory for this pervasive cold bias in the IAS region displayed

126 by the CGCMs suggests that it could also be a result of not resolving the ocean currents

127 sufficiently in the region (e.g. Liu et al. 2013). There is a growing consensus that a grid

128 spacing of $20 \mathrm{~km}$ or less is required at the very least to resolve the Loop Current and the 
129 eddies it spawns (Hurlburt and Thompson 1980; Cherubin et al. 2005, 2006). Liu et al.

130 (2012b, 2015) point to significant ocean circulation bias in the CMIP5 models over the

131 IAS that potentially contribute to the cold bias in SST. To illustrate this, we show the

132 annual mean climatology of SST and its bias from two of the CMIP5 $20^{\text {th }}$ century

133 simulations in Fig. 1: CCSM4 (Gent et al. 2011) and GFDL-ESM2G (Dunne et al. 2012).

134 Both of these model integrations are representative of the pervasive cold SST bias over

135 the IAS that exists across the CMIP5 suite of models (Kozar and Misra 2012). It should

136 however be noted that, despite showing large differences in the magnitude of their cold

137 SST bias (Fig. 1), the two CMIP5 models do not cover the range displayed by the rest of

138 the CMIP5 models. Nonetheless, it is apparent that the cold bias in GFDL-ESM2G over

139 the AWP region is far more severe than in the CCSM4. 

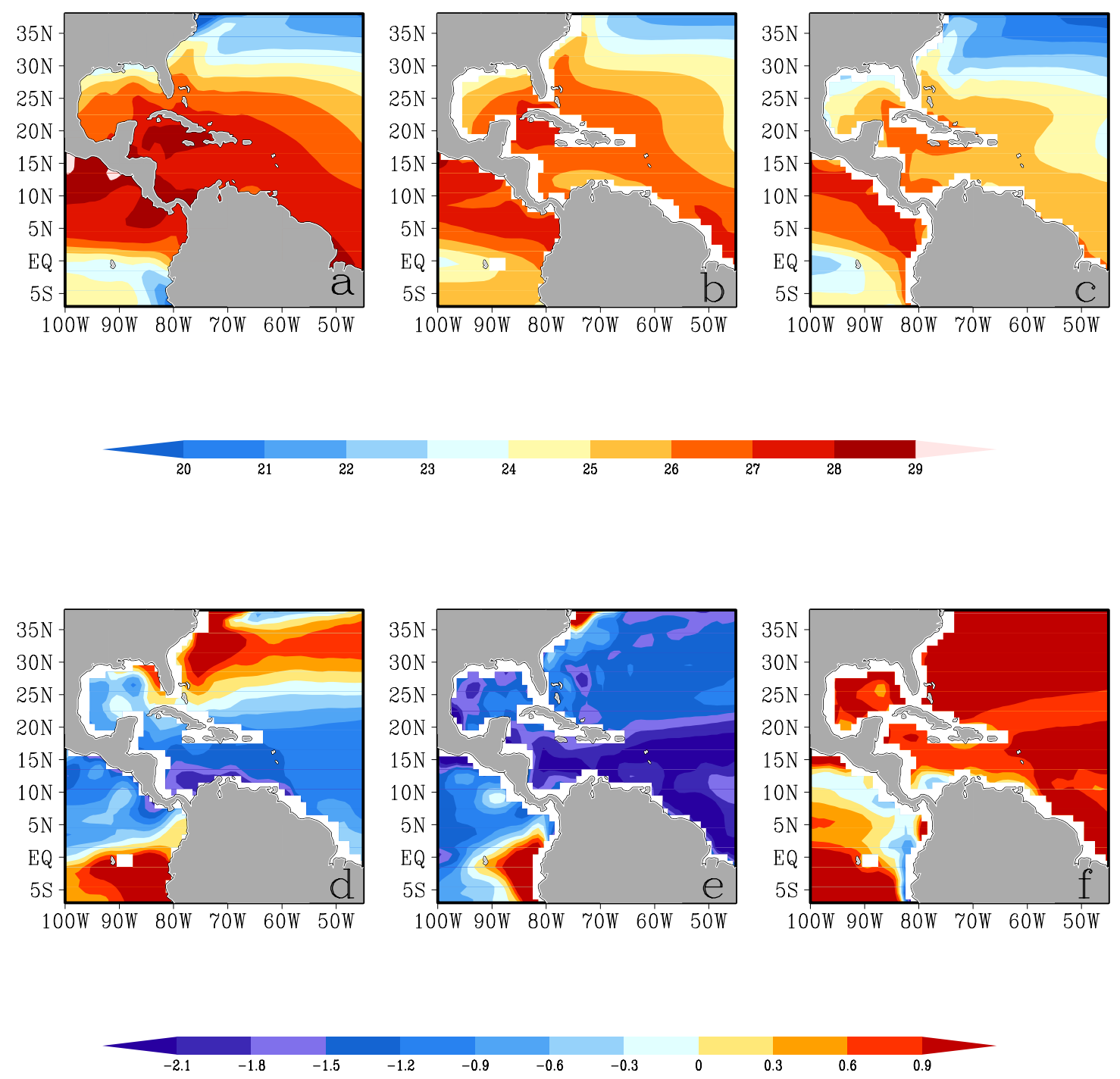

141 Figure 1: Annual mean SST climatology from a) OISSTV2, and $20^{\text {th }}$ century simulations 142 from b) CCSM4, and c) GFDL-ESM2G. The corresponding SST bias from d) CCSM4, 143 and e) GFDL-ESM2G. f) The difference in the annual mean climatology between 144 CCSM4 and GFDL-ESM2G ([CCMS4]-[GFDL-ESM2G]) simulations. The units are in $145{ }^{\circ} \mathrm{C}$.

146 The corresponding monthly mean volume flux through the YC from these two

147 CMIP5 $20^{\text {th }}$ century simulations are presented in Fig 2. For validation, we show the 148 corresponding monthly mean volume flux from the Simple Ocean Data Assimilation 149 version 2.2.4 (SODA; Carton and Giese 2008). While this is not an ideal validation 
150 dataset, it is the closest proxy for observations of ocean transport through the YC

151 available for $\sim 100$ years of the model simulations (1901-2005). SODA assimilates

152 temperature and salinity profiles from the World Ocean Atlas (Mechanical

153 Bathythermograph [MBT], Expendable Bathythermograph [XBT], Conductivity-

154 Temperature-Depth Sonde [CTD], and station data), as well as additional hydrography,

155 SST, and altimeter sea surface height anomalies (Carton and Giese 2008). Moreover,

156 SODA ocean reanalysis is generated by forcing the ocean model with ERA-40 daily

157 atmospheric winds and QuikSCAT winds. Therefore there is a restraint on the model drift

158 from both remote and local ocean observations that results in improved fidelity of SODA.

159 In fact, the volume flux through the YC for a limited time ( $\sim 5$ years $)$ observed from

160 ocean moorings is comparable to the volume flux displayed in SODA ocean reanalysis

161 (Candela et al. 2003; Athie et al. 2015; Fig. 2). Moreover, within these studies of non-

162 overlapping observing periods there is a large disparity in the estimates of observed

163 volume flux through the YC of over $10 \%$, which is attributed to interannual variability

164 (Athie et al. 2015). This called for the use of longer records for model validation of ocean

165 volume flux through YC, which led us to apply data assimilated SODA ocean reanalysis. 


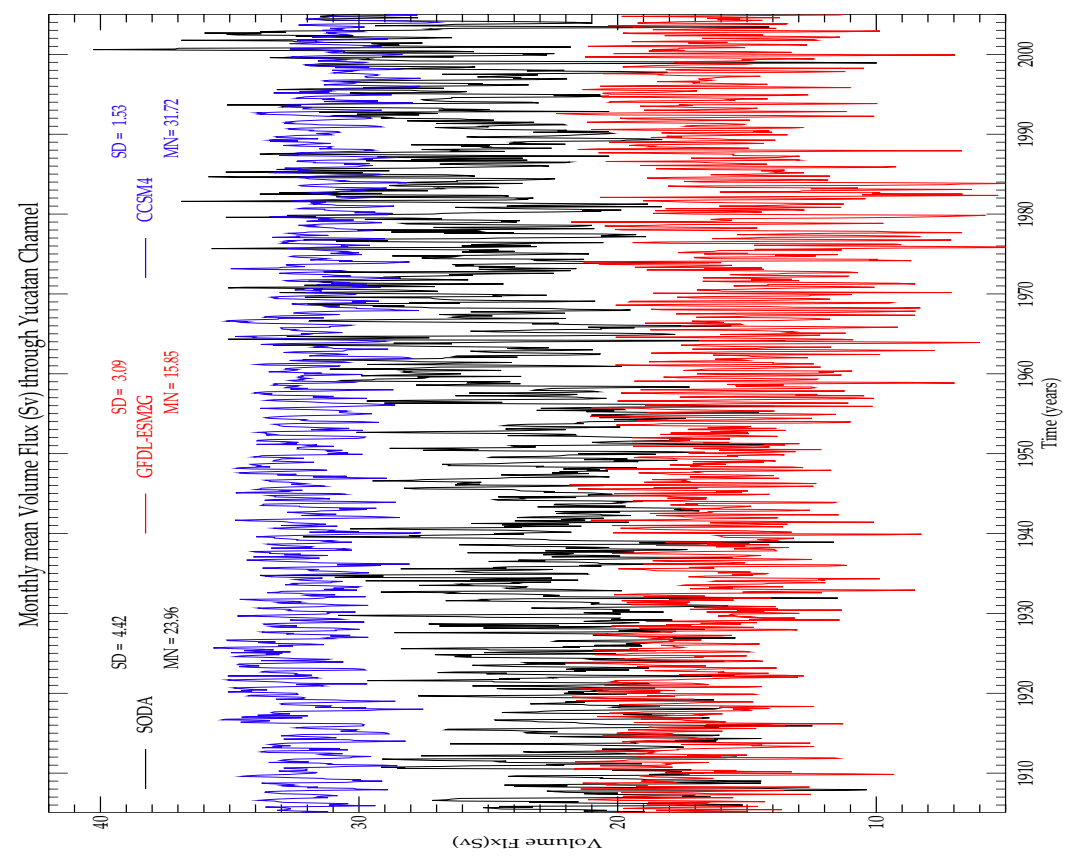

166 Figure 2: The monthly mean volume transport (Sverdrups [Sv]) through the Yucatan 167 Channel from GFDL-ESM2G and CCSM4 20 th century simulations along with the SODA 168 ocean reanalysis from SODA. The corresponding mean (MN) and standard deviation 169 (SD) are also indicated.

170 The climatological monthly mean volume flux through the YC in CCSM4

171 (GFDL-ESM2G) is $31.72 \mathrm{~Sv}(15.85 \mathrm{~Sv})$ while in the SODA ocean reanalysis it is 23.96

172 Sv (Fig. 2). These figures indicate large deviations in the ocean transport through the YC

173 yielded by the two models. It may be noted that the size of the climatological AWP in

174 CCSM4 is almost 60\% more than that in the GFDL-ESM2G (Kozar and Misra 2012),

175 which may be partially a result of the stronger transport through the YC. Furthermore,

176 both models underestimate the volume flux through YC, although GFDL-ESM2G

177 displays slightly higher variability than CCSM4. In Fig. 3 we show the corresponding 
178 heat transport through the YC from the two global models and the SODA ocean

179 reanalysis. The heat flux $(\mathrm{HF})$ through the channel is computed as:

$180 \quad H F=c_{p}^{z_{\text {suff }}} V_{n} d z$

181 where, $C_{p}$ is the heat capacity of seawater $\left(=3993 \mathrm{JKg}^{-1} \mathrm{~K}^{-1}\right), \rho$ is density of seawater,

182 which follows from Jackett et al. (2006), $\mathrm{V}_{\mathrm{n}}$ is the component of the ocean current normal

183 to the channel, and $\theta$ is the potential temperature. This figure clearly shows that the heat

184 transported through the YC in CCSM4 (GFDL-ESM2G) is significantly over-estimated

185 (under-estimated) relative to the SODA ocean reanalysis. However both global models

186 considerably underestimate the size of the AWP relative to the observed SST analysis

187 (Kozar and Misra 2012) and display significant SST bias in the IAS (Fig. 2) despite this

188 diverging bias of ocean heat transport through the YC (Fig. 3). This discussion clearly

189 suggests that the global model bias in ocean circulation in the IAS is substantial. In this

190 study we aim to analyze the response of the SST bias to changes in the IAS ocean

191 circulation in a regional coupled ocean-atmosphere framework. 


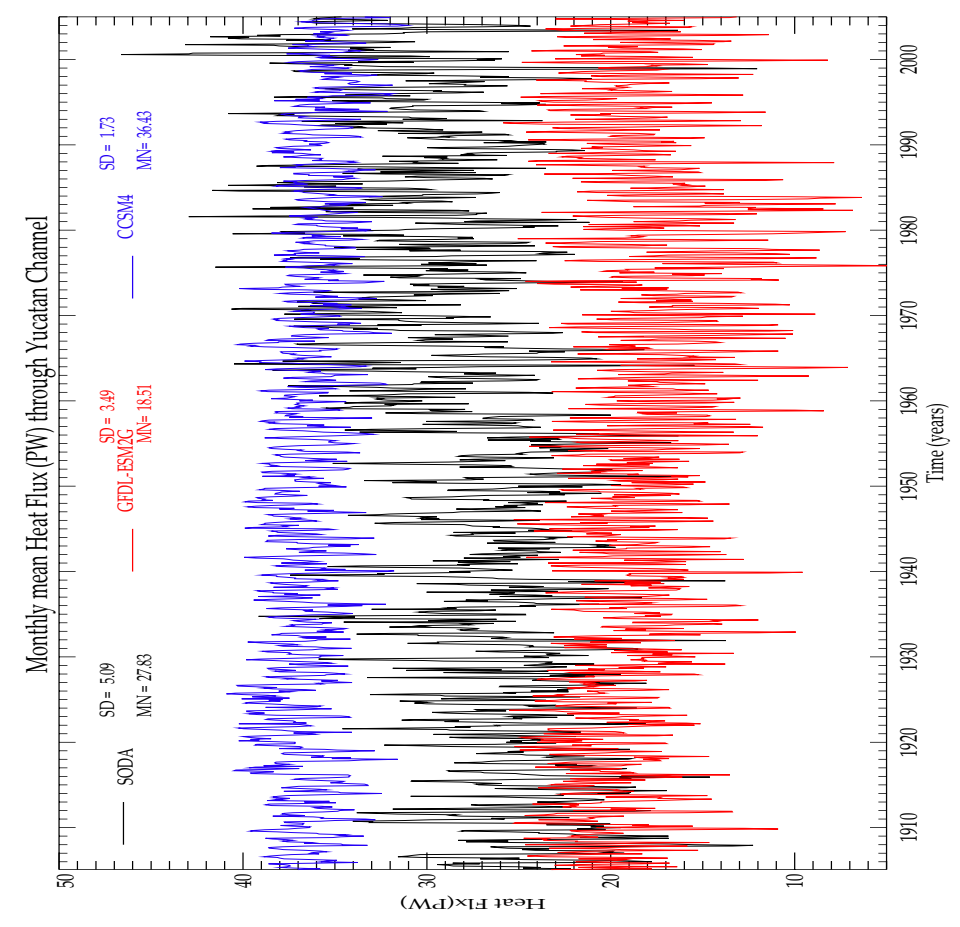

192 Figure 3: Same as Fig.2 for ocean heat transport (in PetaWatts $[P W]=10^{15} \mathrm{~W}$ ) through 193 the Yucatan Channel.

194 3. Model Description

195 Here we provide a brief overview of the regional coupled ocean-atmosphere

196 model (RCM), which follows from the Regional Spectral Model-Regional Ocean

197 Modeling System (RSM-ROMS; Li and Misra 2014). The reader is referred to Li et al.

198 (2012) for a more detailed description of the model and the references therein. This

199 model has been previously adopted in several other regional climate simulations (Li et al.

200 2012, 2013, 2014; Li and Misra 2014; Misra and Mishra 2016). The atmospheric

201 component of the RCM is the RSM that has its origins in Juang and Kanamitsu (1994). It

202 has gone through several updates and revisions and its most current version is described

203 in Kanamitsu et al. (2010). The RSM has 28 terrain following sigma vertical coordinates.

204 An outline of the physics used in the RSM for this study is provided in Table 1. 
Table 1: Outline of the physics in RSM

\begin{tabular}{|c|c|}
\hline Atmospheric Model (RSM) Physics & Reference \\
\hline Land Model & Ek et al. (2003) \\
\hline Longwave radiation & Chou and Suarez (1994) \\
\hline Shortwave radiation & Chou and Lee (1996) \\
\hline Deep convection & Moorthi and Suarez (1992) \\
\hline Shallow convection & Tiedtke (1983) \\
\hline Boundary layer & Hong and Pan (1996) \\
\hline Gravity wave drag & Alpert et al. (1988) \\
\hline
\end{tabular}

Similarly, the ROMS version 3.0 uses a stretched terrain following (S) coordinate

207 for vertical discretization on a horizontal staggered Arakawa-C grid (Haidvogel et al.

208 2000; Shchepetkin and McWilliams 2005). There are 30 sigma-levels in ROMS. The

209 local closure scheme for mixing is based on the level 2.5 turbulent kinetic energy

210 equations following Mellor and Yamada (1982) and generic length scale parameterization

211 of Umlauf and Burchard (2003). The nonlocal closure scheme is based on the K-profile,

212 boundary layer formulation developed by Large et al. (1994).

213

\section{Experiment Design}

The regional domain over which the RCMs are integrated at $15 \mathrm{~km}$ grid interval is

216 shown in Fig. 4. The three RCM integrations are conducted independent of each other but

217 over identical domain and resolution (Fig. 4): The first integration, which follows the use

218 of a smoother bathymetry, is RCM-C; The second, RCM-F, uses a finer bathymetry; and

219 the third, RCM-I, has a bathymetry of intermediary realism between RCM-C and RCM-

220 F. The bathymetries for all of these model integrations stem from ETOPO5

221 (http://www.ngdc.noaa.gov/mgg/global/etopo5.HTML), which is available at 5-minute 
222 resolution. All three RCM simulations are conducted for a 32-year period from 1979

223 through 2010. They are forced at the lateral boundaries of the atmosphere with the 6

224 hourly atmospheric fields of the National Centers for Environmental Prediction-

225 Department of Energy atmospheric reanalyis (NCEP-R2; Kanamitsu et al. 2002) and the

226 monthly mean SODA ocean reanalysis as the lateral boundary forcing for ROMS. 

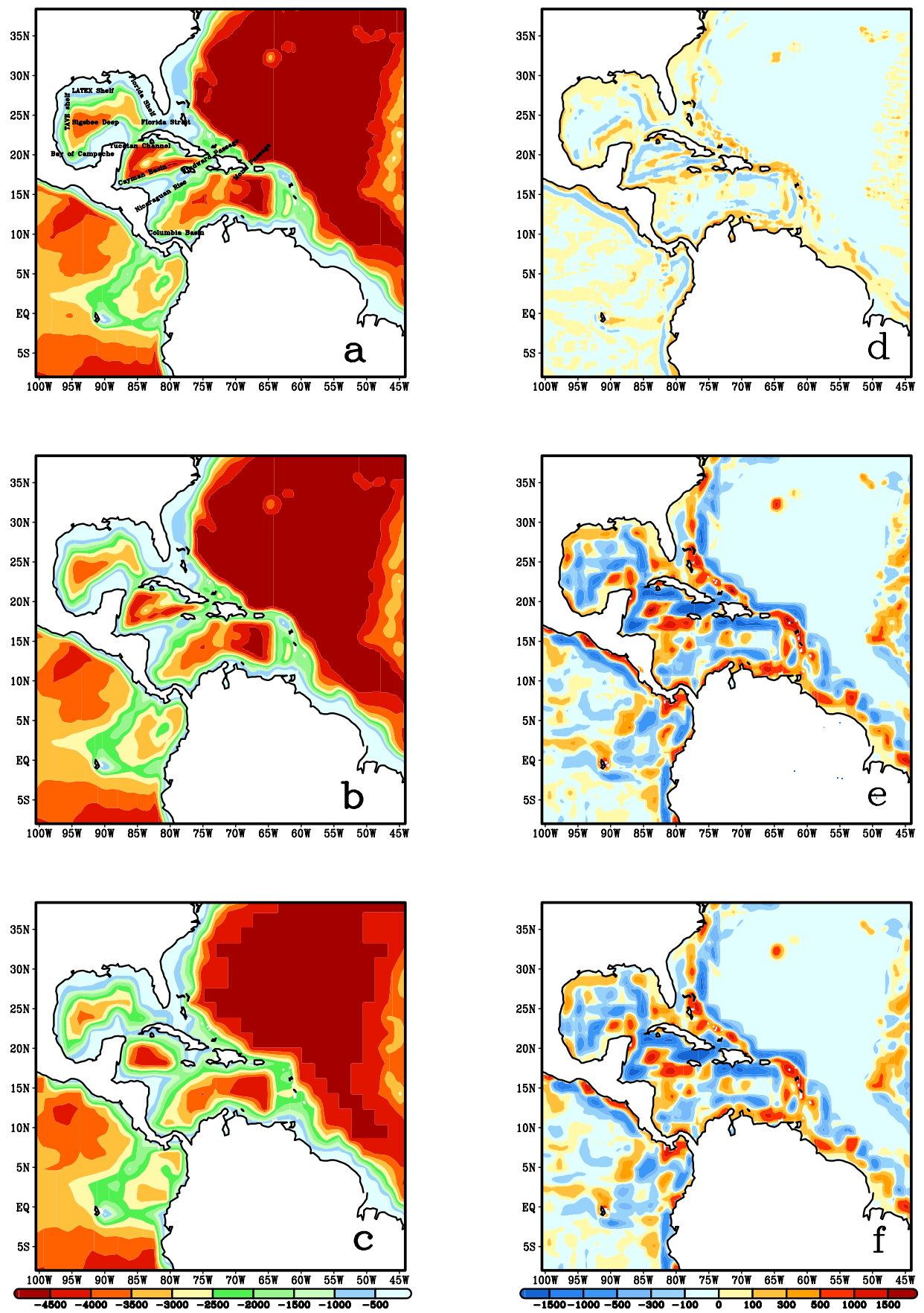

228 Figure 4: The regional domain overlaid with bathymetry used in a) RCM-F with 229 important features named, b) $R C M-I$, and c) RCM-C. The differences in bathymetry 230 between them are shown in d) (RCM-F)-(RCM-I), e) (RCM-F)-(RCM-C), and f) (RCM-I)231 (RCM-C). The units are in meters. 
232 We also use the SODA ocean reanalysis and the World Ocean Atlas (WOA; Locarnini et

233 al. 2013) to compare with the multi-decadal RCM model integrations. Despite its

234 prevalent uncertainties, the SODA ocean reanalysis serves as a good verification dataset

235 given its availability for a relatively long time record (Giese and Ray 2011). There are,

236 however, extensive field programs such as CANEK (Sheinbaum et al. 2002) that have

237 yielded useful information on the seasonal cycle and quantitative estimates of the 238 discharge through the YC. But considering the uncertainty of the IAS from the natural

239 variations (e.g. Loop Current variations; Leben 2005; Dukhovskoy et al. 2014; Athie et

240 al. 2015), we believe it is reasonable to use the data assimilated SODA ocean reanalysis

241 to verify the ocean climate from the conducted multi-decadal model simulations. The

242 WOA data available at $0.25^{\circ}$ grid spacing is an objectively analyzed annual mean

243 temperature profile using six decades of data (1955-2012) available from the National

244 Oceanographic Data Center and the World Data Center for Oceanography at standard

245 depth levels from surface to a maximum depth of 5500m (Locarnini et al. 2013). The

246 initial conditions for RSM-ROMS are interpolated from the corresponding global

247 atmospheric and oceanic reanalysis for 1 January 1979. These initial conditions are

248 identical for all three RCM integrations, however we neglect the first five years of the

249 model integration for the analysis of the results to account for spin-up issues. We use the

$250 \quad 1984-2010$ (27 year) period for the analysis of the results discussed in this paper.

251 In RCM-I, we smooth the bathymetry from ETOPO5 by first running a 5-point 252 smoother prior to linearly interpolating to the $15 \mathrm{~km}$ grid of the ROMS; in the RCM-C,

253 we linearly interpolate the original bathymetry to $\sim 200 \mathrm{~km}$ grid resolution (or T62

254 spectral truncation) before we interpolate it to the $15 \mathrm{~km}$ ROMS grid. The smoothing in 
255 the RCM-I is necessary to avoid numerical instability in the middle of the integration.

256 The bathymetry for RSM-F is obtained by taking the average of the original ETOPO5

257 bathymetry and the bathymetry of RSM-I. The most notable impact of such a change is

258 that the depth and extent of the continental shelf regions in RSM-F increases relative to

259 RSM-I. In ROMS, which has a terrain following vertical coordinate system, the usual

260 practice is to smooth the bathymetry to reduce errors in the computation of the horizontal

261 pressure gradient (Mellor et al. 1994; Haidvogel et al. 2000; Martinho and Batteen 2006;

262 Sikiric et al. 2009). Haney (1991) showed that ocean models with terrain following

263 vertical coordinate system could have large errors in computing the horizontal pressure

264 gradient, especially in regions of steep terrain. Therefore, based on the choice of the

265 vertical coordinate system, the bathymetry may have to be altered to accommodate

266 numerically stable solutions (Sikiric et al. 2009). More sophisticated approaches to

267 smooth the bathymetry than what is adopted here do exist (Sikiric et al. 2009) and we

268 will pursue these alternative methods in future studies. The differences in bathymetries

269 (Figs. 4d, e, and f) are apparent over several regions including: over the Colombian

270 Basin, the Cayman Basin, the Nicaraguan Rise, the YC, the Sigsbee Deep, the Bay of

271 Campeche, the Continental Shelf areas of the GoM, and over the Florida Straits (see Fig.

272 1a for their geographical location). In all of these regions the differences in the

273 bathymetry range from a few meters to $1500 \mathrm{~m}$ or more. It should be noted that in Fig. 4e

274 the YC in RCM-F is narrower in width and deeper in depth than in the RCM-C

275 bathymetry. Furthermore, in Fig. 4e we see that the bathymetry in the Florida Straits

276 between Florida and Cuba is deeper in RCM-F as compared to RCM-C. In addition, the

277 continental shelf along Louisiana and Texas (known as the LATEX shelf) and along 
278 Tamaulipas-Veracruz in Mexico (the TAVE shelf) is deeper and extends further out in 279 the GoM in RCM-C as compared to RCM-F. Similarly, the Windward and Mona 280 passages are very shallow in RCM-C as compared to RCM-F. The differences between

281 RCM-F and RCM-I (Fig. 4d) are comparatively smaller but share similar sign as the 282 differences of bathymetry between RCM-F and RCM-C. Likewise, the differences 283 between RCM-I and RCM-C (Fig. 4f) are similar in sign but larger in magnitude to those 284 between RCM-F and RCM-I (Fig. 4d). However, an important difference is that the

285 Windward and Mona passages in the bathymetry of RCM-F are a bit more realistic (and 286 deeper) than that of RCM-I and RCM-C. As will be discussed in the following section, 287 these differences in the bathymetry lead to some significant changes in the ocean 288 simulation despite the identical grid resolution of RCM-C, RCM-I, and RCM-F.

289 For verification of the ocean surface currents we make use of the Ocean Surface

290 Current Analysis (OSCAR; Bonjean and Lagerloef 2002; Helber et al. 2007), which is

291 available at $1 / 3^{\circ}$ grid resolution from 1993 to the present and is derived from satellite

292 altimeter and scatterometer winds. It is worth noting that when comparisons of the model

293 simulations are made with OSCAR it is based on the overlapping period (1993-2010)

294 only. Similarly, we use the optimally interpolated SST version 2 (OISSTv2; Reynolds et

295 al. 2007) available at $0.25^{\circ}$ grid resolution for verification of the simulated SST. We also

296 employ the Coordinated Ocean-ice Reference Experiments Phase 2 hindcast simulations

297 (COREII; Large and Yeager 2009) to verify the atmospheric fluxes from the model.

298 COREII makes use of NCEP reanalysis for near surface meteorological fields along with

299 a variety of satellite based radiation, SST, sea-ice concentration, and precipitation

300 products to arrive at the atmospheric fluxes for the $1984-2006$ period at $1^{\circ}$ grid spacing. 
301 The balance of this paper's discussion focuses on the IAS and the western tropical and

302 subtropical-Atlantic Ocean (AWP region) despite the fact that the regional domain covers

303 parts of the tropical eastern Pacific Ocean.

304

305

306

307

308

309

310

311

312

313 Stream) are apparent (Figs. 5d, e, and f). As evidenced in Fig. 5, all three RCM

314 simulations display a pervasive cold SST bias over the IAS. However it is important to

315 note that the SST bias along the coasts in Figs. 5d, e, and f may also be partly on account

316 of the differences in the resolution of the RSM-ROMS and OISSTv2. Nonetheless, Fig.

317 5h shows that for large portions of the IAS, the cold bias in RCM-C seems to be more 318 acute than in RCM-F, especially along the southern limb of the Gulf Stream as well as

319 over the Loop Current region of the GoM and in parts of tropical and subtropical western

320 Atlantic Ocean. There are regions over the southern Caribbean Sea, along the LATEX

321 shelf, along the northeast coast of GoM, and along western shelf of peninsular Florida

322 where the RCM-C is warmer and depicts less bias than RCM-F (Fig. 5h). We note that

323 RCM-I improved upon the cold bias of the RCM-F in the western GoM and over the

324 southern Caribbean Sea (Fig. 5g). In the tropical western Atlantic Ocean and along the 
325 Gulf Stream (off the coast of the Carolinas) the RCM-F is seen as an improvement over 326 RCM-I (Fig. 5g).
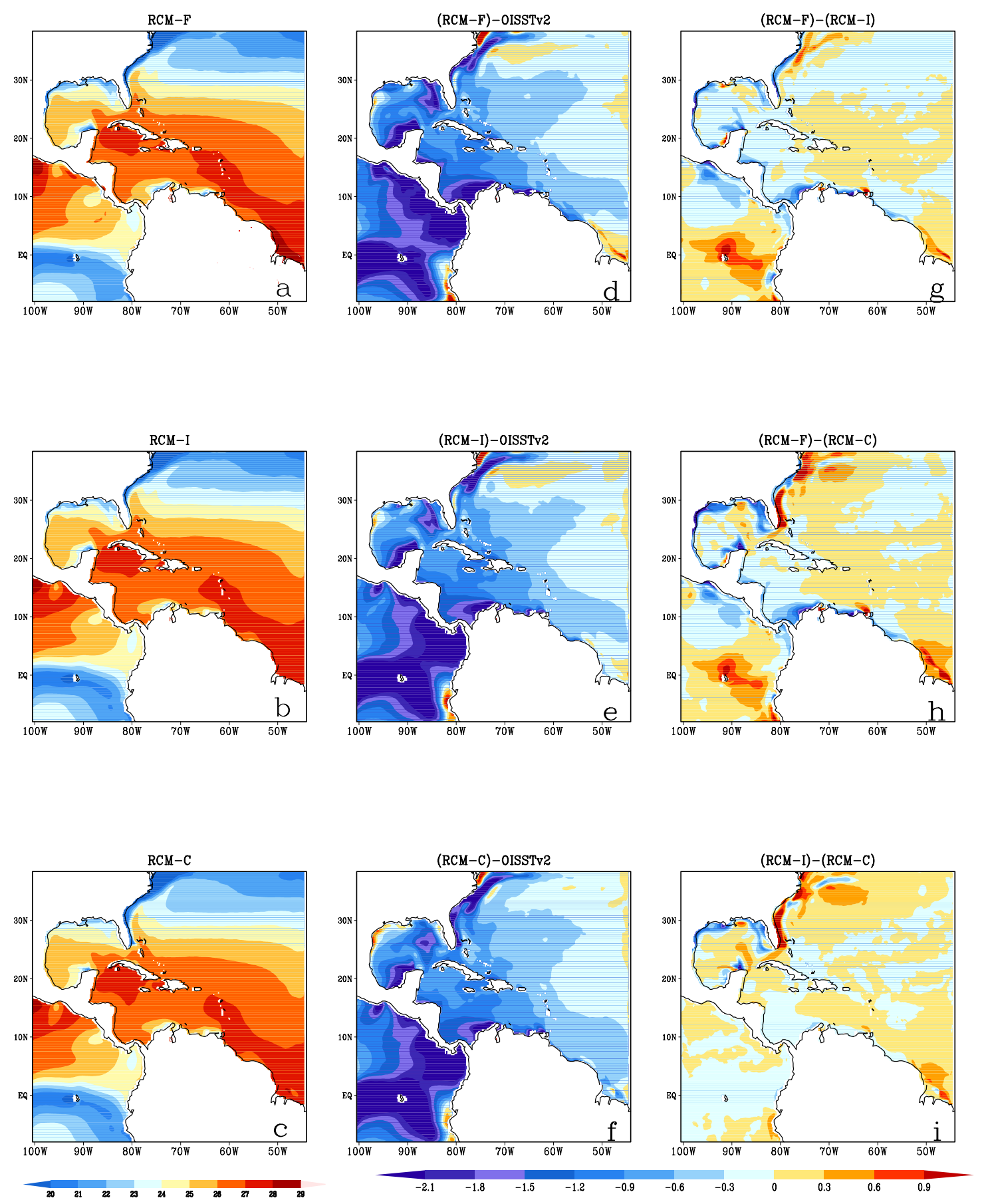

328 Figure 5: The climatological annual mean $\operatorname{SST}\left({ }^{\circ} \mathrm{C}\right)$ from a) $\left.R C M-F, b\right) R C M-I$, and $c$ ) 329 RCM-C simulations. The corresponding SST bias $\left({ }^{\circ} \mathrm{C}\right)$ from $d$ ) RCM-F (RCM-F330 OISSTv2), e) RCM-I (RCM-I-OISSTv2), and f) RCM-C (RCM-C-OISSTv2) simulations. 
331 The difference in the climatological annual mean SST between $g$ ) RCM-F and RCM-I, $h$ ) $332 R C M-F$ and $R C M-C$, and i) RCM-I and RCM-C simulations $\left({ }^{\circ} \mathrm{C}\right)$.

333
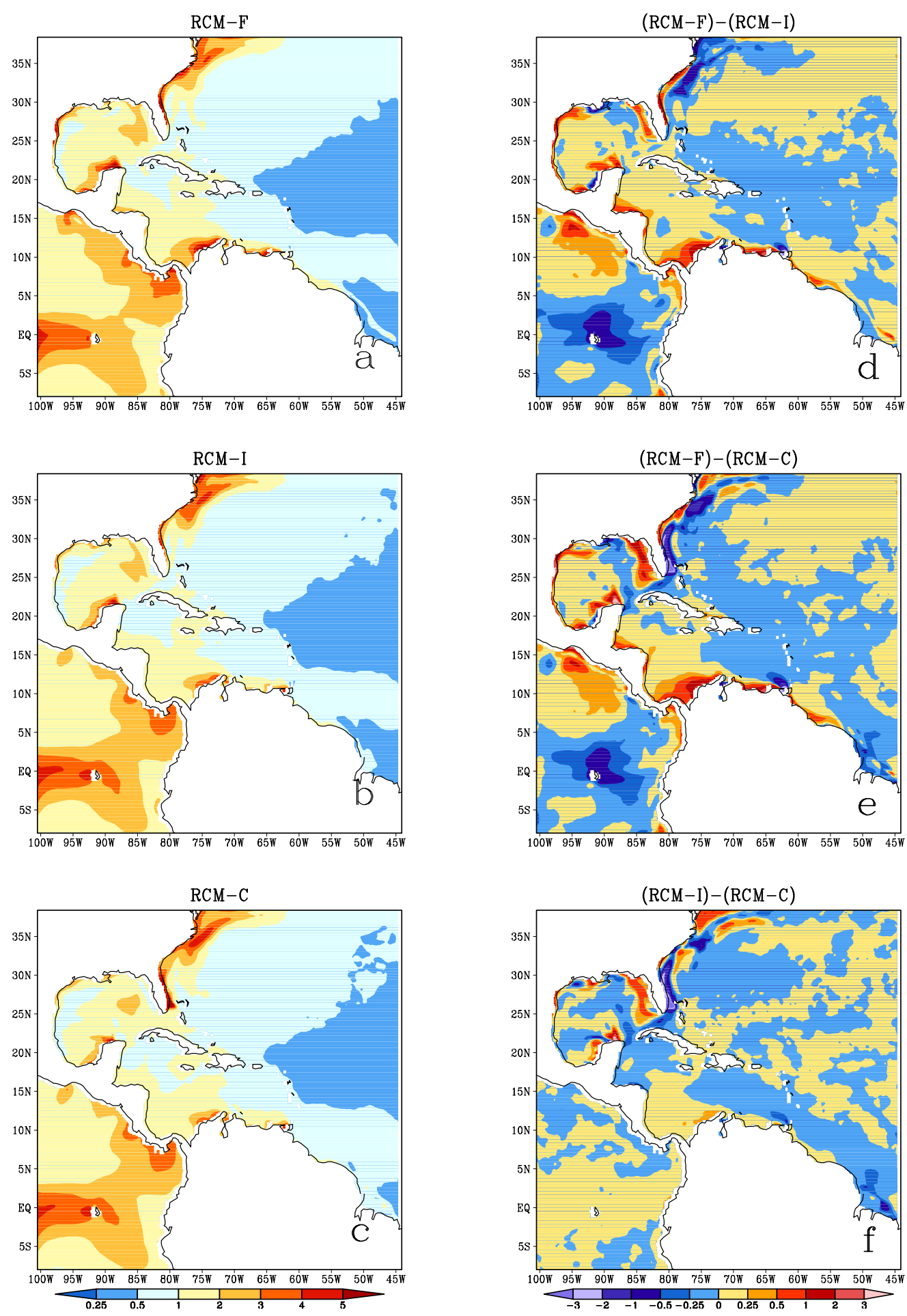
335 Figure 6: The root mean square error (RMSE) of the climatological annual mean SST 336 from a) $R C M-F, b) R C M-I$ and c) RCM-C simulations. The corresponding differences of 337 RMSE between d) RCM-F and RCM-I, e) RCM-F and RCM-C and f) RCM-I and RCM-C. 338 and c) their corresponding RMSE difference (RCM-C-RCM-F). The units are in ${ }^{\circ} C$.

339 The root mean square error (RMSE) of SST from RCM-F, RCM-I, and RCM-C

340 relative to OISSTv2 are illustrated in Figs. 6a, b and c respectively. The differences

341 between these RMSEs and the RCM simulations are shown in Figs. 6d, e, and f. As

342 mentioned with regards to Fig. 5, we see in Fig. 6 that RCM-F improves upon RCM-I

343 and RCM-C over parts of the tropical and subtropical western Atlantic Ocean while

344 RCM-I improves upon RCM-C and RCM-F over northern Caribbean Sea and western

345 GoM (Figs. 6e and f). In other words, a more realistic bathymetry will not necessarily

346 alleviate (and can even further deteriorate) the SST biases of a model simulation in

347 isolated regions that could be emanating from other sources of model errors. These

348 systematic differences in SST between RCM-F, RCM-I, and RCM-C merit further

349 investigation. First, the different bathymetries are expected to change the circulation

350 especially through the $\mathrm{YC}$ and other passages in the region. These changes will

351 potentially provide a good source for investigation of the importance of ocean circulation

352 on the regulation of SST over the IAS. Second, understanding the differences in the SST

353 between RCM-F, RCM-I, and RCM-C, which is similar to the pervasive cold bias

354 displayed over the IAS by Coupled General Circulation Models (CGCM's; Misra et al.

355 2009; Kozar and Misra 2012; Liu et al. 2012, 2013), may provide some insights for

356 improving future generations of CGCM. 

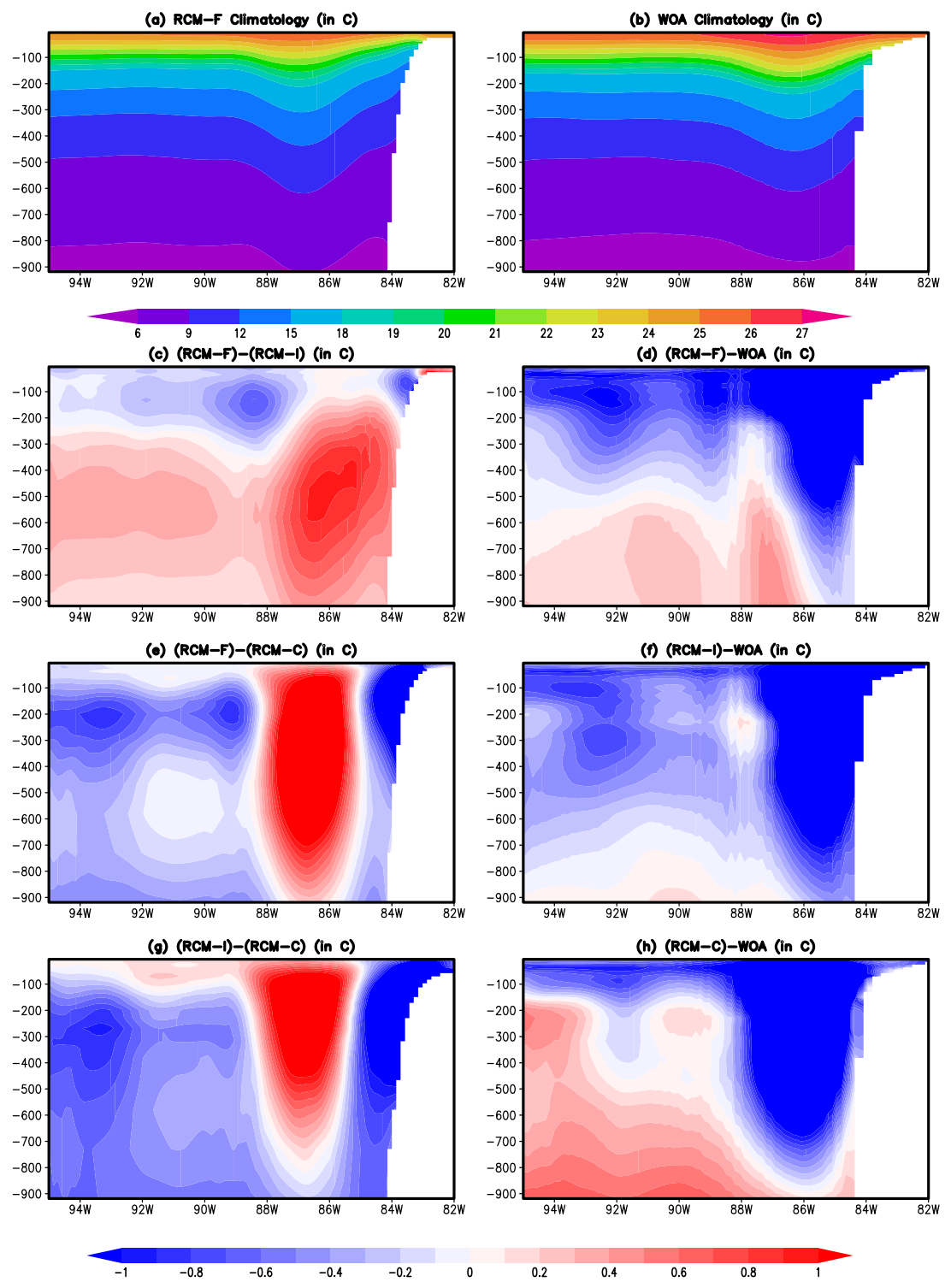

$358 \quad$ Figure 7: Vertical cross-section of the climatological annual mean temperature $\left({ }^{\circ} \mathrm{C}\right)$ at $35925^{\circ} \mathrm{N}$ (along central GoM) from a) RCM-F and $b$ ) WOA. The corresponding difference of 360 RCM-F from c) RCM-I (RCM-F-RCM-I), e) RCM-C (RCM-F-RCM-C) and $g$ ) the 361 difference (RCM-I)-(RCM-C). Similarly the corresponding systematic errors from $d$ ) $362 \quad R C M-F, f) R C M-I$ and $h$ ) $R C M-C$.

363 In Fig. 7, a cross section along $25^{\circ} \mathrm{N}$ in the central GoM from RCM-F (Fig. 7a)

364 and its corresponding differences with RCM-I (Fig. 7c), RCM-C (Fig. 7e) can be seen.

365 Similarly, the corresponding observed cross section from WOA (Fig. 7b) and the 
systematic errors in RCM-F (Fig. 7d), RCM-I (Fig. 7f), and RCM-C (Fig. 7h) can also be

367 seen. The figure clearly indicates that the relative warming of RCM-F compared to RCM-

368 I and RCM-C in the Loop Current flow is rather large. However, the temperatures in

369 RCM-F in the first $200 \mathrm{~m}$ from the surface are cooler to the west of the Loop Current

370 when compared to both WOA (Fig. 7d) and the other two model simulations (Figs. 7e

371 and g). Interestingly, below 200m RCM-F is significantly warmer than RCM-I (Fig. 7c)

372 but it is still cooler than RCM-C (Fig. 7e). In addition, the warming in the western GoM

373 (west of 88W) in RCM-I relative to RCM-C (Fig. 7g) is rather shallow near the surface of

374 the ocean. Overall, the systematic errors of RCM-I in this cross section is less than in the

375 other two simulations.

376

377 b) Atmospheric fluxes

378 As seen in Fig. 8a, the annual mean climatological atmospheric net heat flux in

379 RCM-F is largely positive in the AWP region (south of around $23^{\circ} \mathrm{N}$ ). A positive

380 (negative) net heat flux in this case would mean that the heat flux is directed downward

381 (upward) to (from) the ocean surface. Therefore, in RCM-F there is more net heat flux

382 entering the ocean surface from the atmosphere in the IAS and over western tropical

383 Atlantic Ocean relative to RCM-I (Fig. 8b) and RCM-C (Fig. 8c). Despite this excess

384 heat flux entering the ocean surface (Fig. 8b), RCM-F displays a more severe cold bias

385 over the western GoM and in the Caribbean Sea as compared to RCM-I (Fig. 5g). On the

386 other hand, RCM-I has less heat flux going into the ocean over the central GoM, Bay of

387 Campeche, northern Caribbean Sea, and the northwestern subtropical Atlantic Ocean

388 relative to RCM-F (Fig. 8b) and RCM-C (Fig. 8d). Yet over these regions the SST is 
390 contrarian differences in atmospheric fluxes between the model integrations are clearly

391 insufficient to explain the differences in SST between the model simulations (Fig. 5).
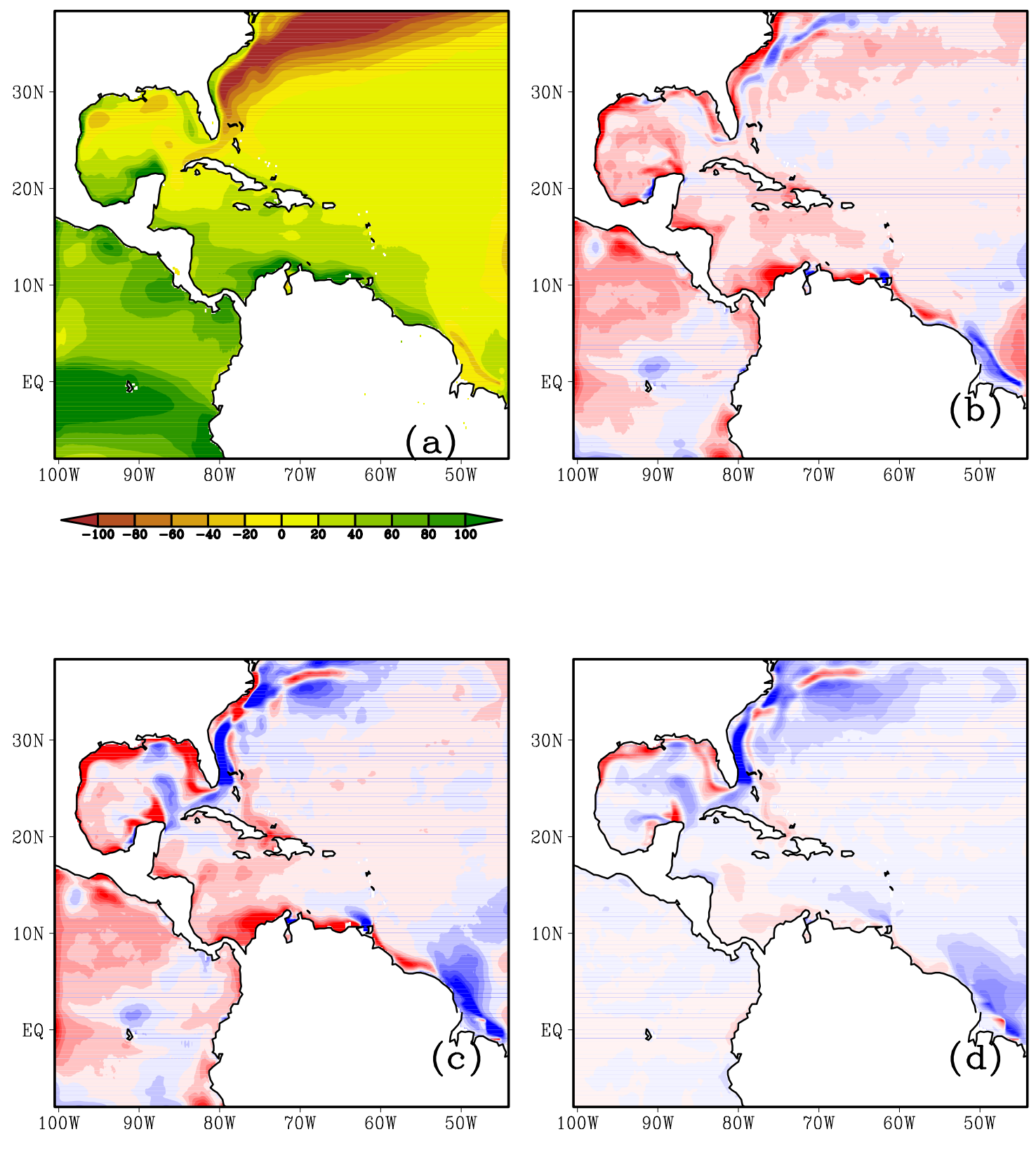

\section{$\begin{array}{llllllllll}5 & 10 & 15 & 20 & 25 & 30 & 35 & 40 & 45 & 50\end{array}$}

393 Figure 8: a) The net heat climatological annual mean atmospheric flux from the RCM-F 394 simulation and the corresponding difference with b) RCM-I and c) RCM-C simulations. 
395 d) The net het climatological annual mean atmospheric flux difference between RCM-I 396 and $R C M-C$. The units are in $\mathrm{Wm}^{-2}$.

\section{c) Upper Ocean Heat Content}

$399 \quad$ Figs. 9a, b and c show the annual mean climatological depth of the $20^{\circ} \mathrm{C}$ (a proxy 400 for the upper ocean heat content) from the RCM-F, RCM-I, and RCM-C integration 401 respectively. The corresponding bias in RCM-F, RCM-I, and RCM-C are illustrated in 402 Figs. 9d, e, and f respectively, while the differences between RCM simulations are shown 403 in Figs 9g, $\mathrm{h}$, and i. In relation to the SODA ocean reanalysis, all three RCM simulations 404 underestimate the heat content in the GoM, the Caribbean Sea, and parts of the western 405 tropical Atlantic Ocean (Figs. 9d-f). These errors are most exacerbated in RCM-F over

406 the western GoM and the western Caribbean Sea (Figs. 9g-i). We observe a relative 407 deepening of the $20^{\circ} \mathrm{C}$ isotherm in RCM-F over the tropical and subtropical western 408 Atlantic Ocean relative to RCM-I and RCM-C (Figs. 9g and h), however RCM-I displays 409 the largest improvement in this bias over the IAS relative to the other two RCM 410 simulations. 

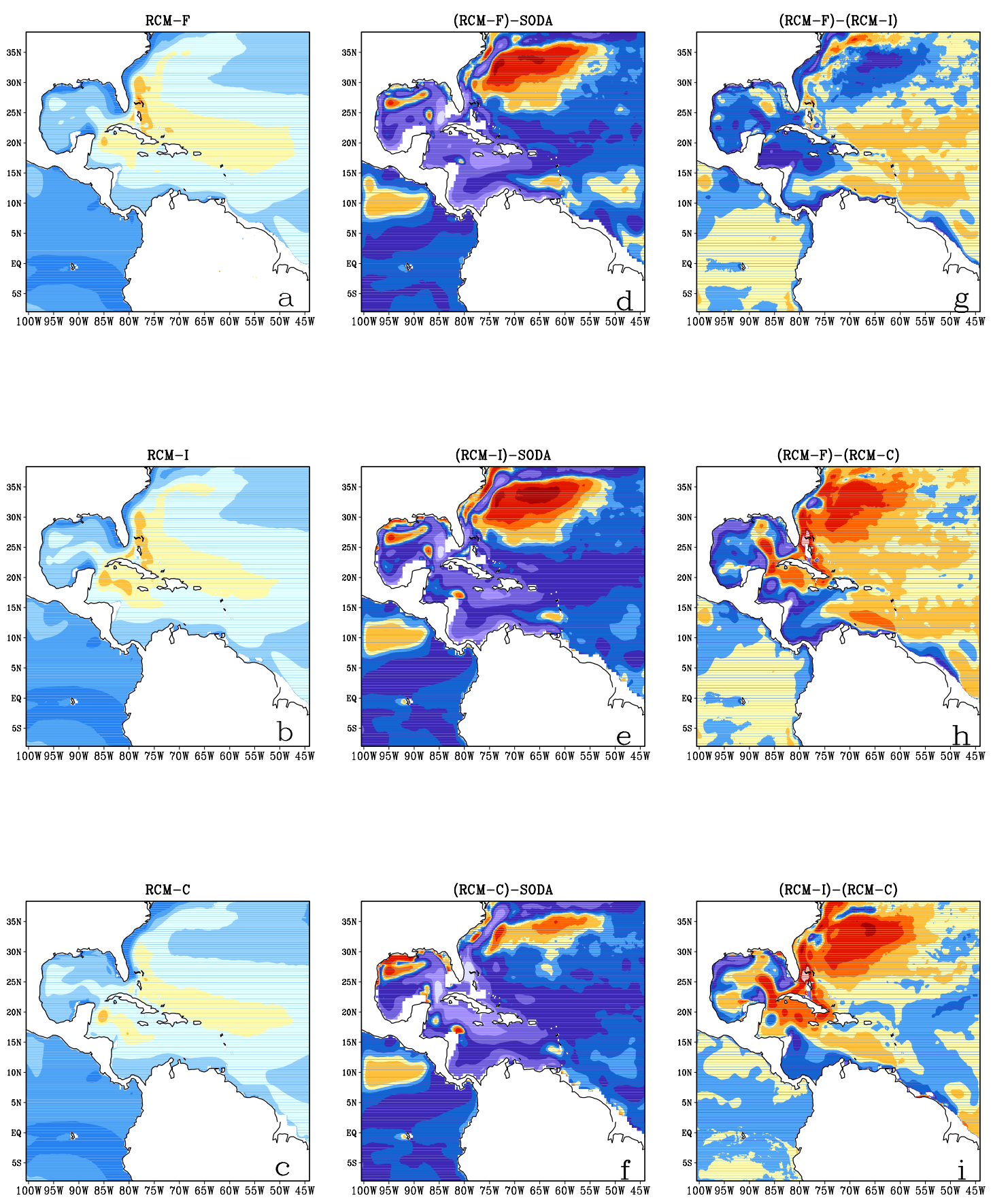

411
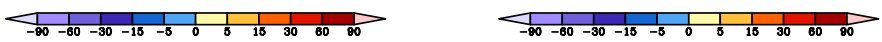

412 Figure 9: Same as Fig. 5 but for the annual mean climatological depth of the $20^{\circ} \mathrm{C}$ 413 isotherm. SODA ocean reanalysis is used for validation. The units are in $\mathrm{m}$. 
(a) RCM-F

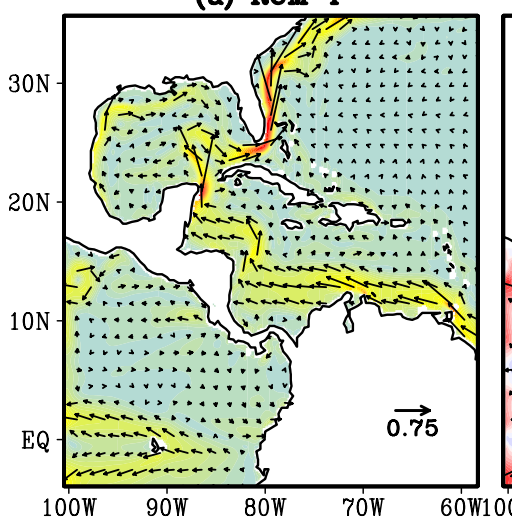

(b) RCM-I

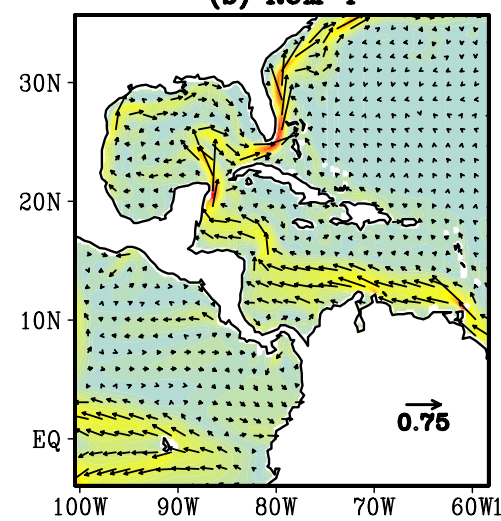

(c) $\mathrm{RCM}-\mathrm{C}$

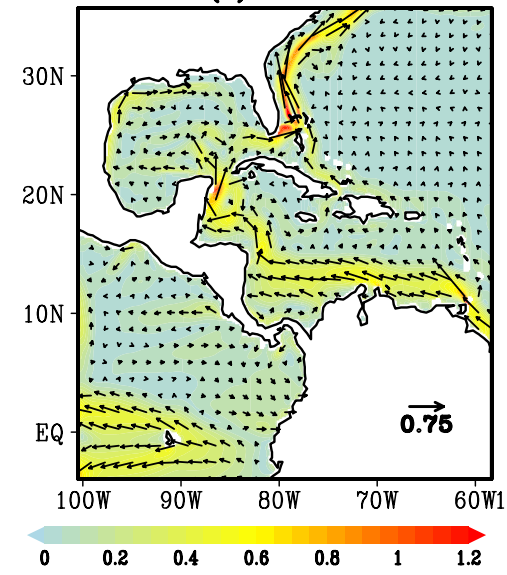

(d) (RCM-F)-OSCAR

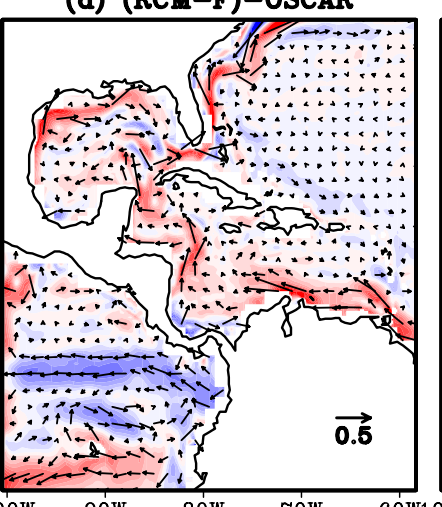

(e) (RCM-I)-OSCAR

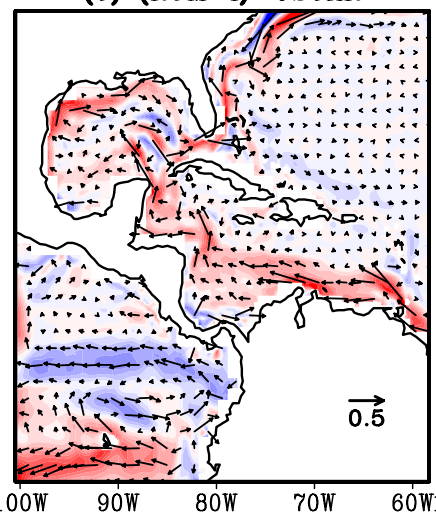

(f) (RCM-C)-OSCAR

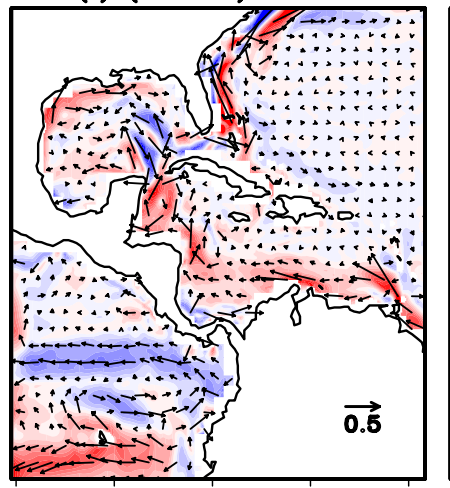

$\begin{array}{rrrrrr}-0.5 & -0.4 & -0.3 & -0.2 & -0.1 & 0\end{array}$ (g) (RCM-F) - (RCM-I)

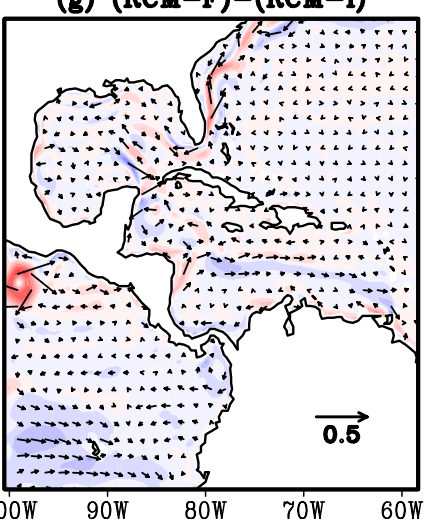

(h) (RCM-F)-(RCM-C)

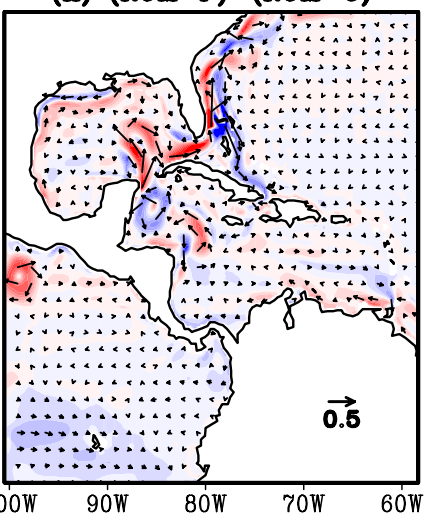

(i) (RCM-I)-(RCM-C)

415 Figure 10: Same as Fig. 5 but for surface ocean currents and OSCAR (Bonjean and 416 Lagerloef 2002) is used for validation. The units are in $\mathrm{m} / \mathrm{s}$.

417

418

d) Ocean Currents 
420 RCM-C are shown in Figs. 10a, b, and c respectively. The biases of these currents in the

421 RCM simulations indicate that the surface westward Caribbean currents are stronger than

422 the observations (Figs. 10d-f). But unlike the other two simulations, RCM-C has a

423 considerably weaker surface Loop Current and surface flow along the Florida Current

424 (Figs. 10f, h, and i). RCM-F displays the strongest surface Loop Current of all three

425 RCM simulations, although its difference from RCM-I is comparably far smaller (Fig.

$42610 \mathrm{~g}$ ) than that from RCM-C (Fig. 10h). Furthermore, the northward extension of the

427 Loop Current is extremely weak in RCM-C while the meridional current of the Florida

428 Current is shifted further eastward in RCM-C relative to the observations and the other

429 RCM simulations.

430 Figs. $11 \mathrm{a}, \mathrm{b}, \mathrm{c}$, and d show the cross section of the climatological annual mean

431 flow through the YC in SODA ocean reanalysis, RCM-F, RCM-I, and RCM-C

432 integrations respectively. The differences in the bathymetry of the YC between the

433 SODA, RCM-F and RCM-C simulations are quite apparent in the figure, although the

434 differences of the flow through YC and the bathymetry between RCM-F (Fig. 11b) and

435 RCM-I (Fig. 11c) are comparably much smaller. In RCM-C (Fig. 11d) the channel depth

436 is appreciably shallower than in the RCM-F, RCM-I and SODA ocean reanalysis.

437 Therefore the meridional flow through the channel is also significantly different in RCM-

438 C relative to RCM-F and SODA. For example, the meridional current through the YC

439 shows the asymmetric maximum northward flow on the westward side of the channel in

440 SODA ocean reanalysis (Fig. 11a) and RCM-F simulation (Fig. 11b). This asymmetry in 
441 the flow near the surface through the YC is progressively reduced in RCM-I (Figs. 11c 442 and e) and RCM-C (Figs. 11d, f, and g).

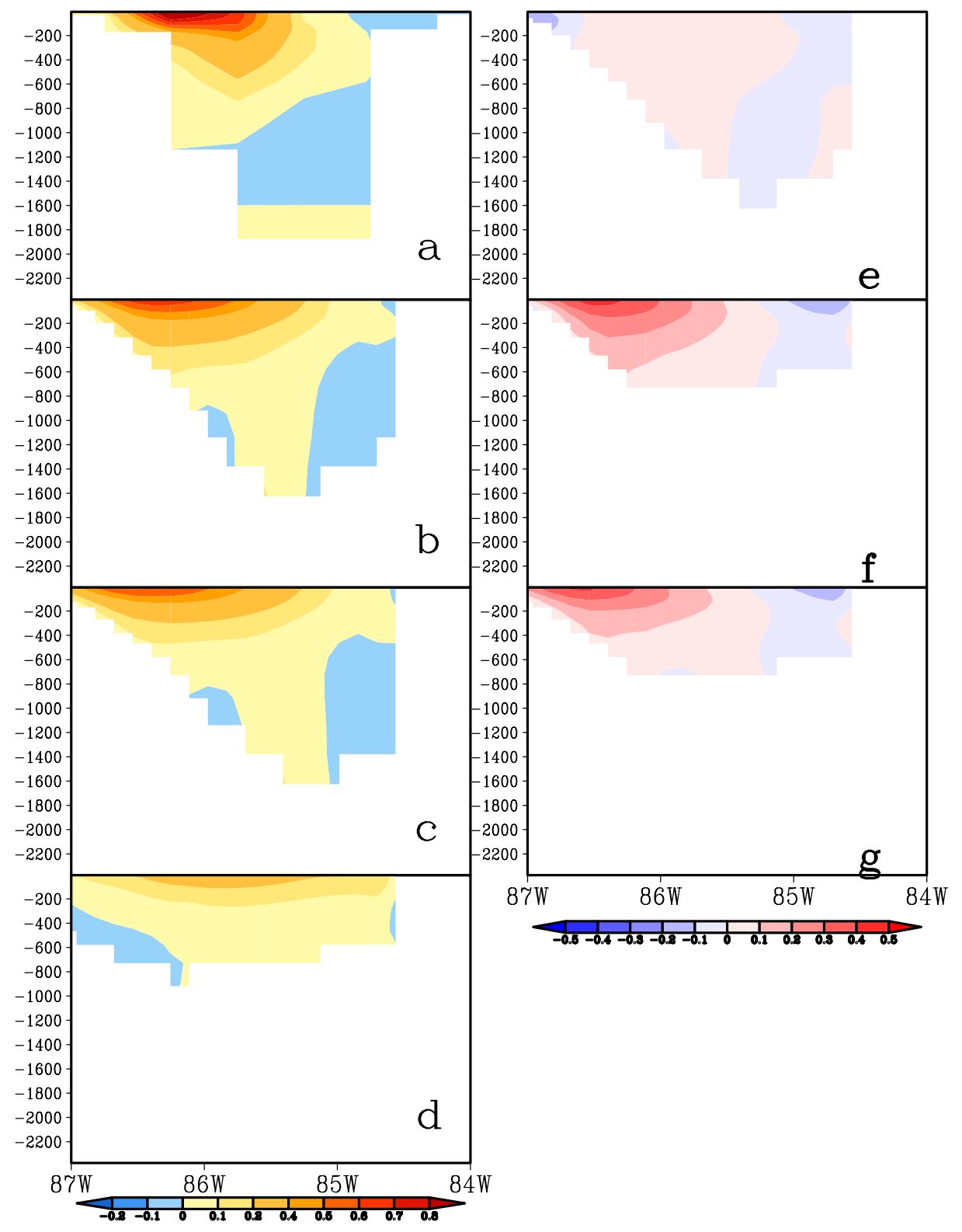

444 Figure 11: Vertical cross section of the meridional flow $\left(\mathrm{ms}^{-1}\right)$ through the Yucatan 445 Channel from a) SODA ocean reanalysis, b) RCM-F, c) RCM-I, and d) RCM-C 446 integrations. The corresponding differences $\left(\mathrm{ms}^{-1}\right)$ between e) (RCM-F)-(RCM-I), $447 f)(R C M-F)-(R C M-C)$, and $g))(R C M-I)-(R C M-C)$ are also shown. 
448 The maximum surface meridional speed in the RSM-F is approximately $0.7 \mathrm{~ms}^{-1}$ (Fig.

449 11b), which is less than the maximum in SODA ocean reanalysis that display a maximum 450 of around $1.1 \mathrm{~ms}^{-1}$ (Fig. 11a). The RCM-F (Fig. 11b) and RCM-I (Fig. 11c) integrations

451 also produce counter currents on both the Yucatan and Cuban sides of the channel, below

452 around $400 \mathrm{~m}$ as is mentioned in the observational study of Candela et al. (2003). The

453 SODA reanalysis, however, shows the counter current across the channel at around

$4541000 \mathrm{~m}$ below the surface, which is contrary to the observations made by Candela et al.

455 (2003), who asserted that there is a persistent weak flow toward the GoM in the central

456 deepest part of the channel surrounded by the counter currents on either side. In Fig. 11a,

457 we also note a surface counter current identified in Candela et al. (2003) as the Cuban

458 counter current, which extends to $200 \mathrm{~m}$ in depth. The RCM-F (Fig. 11b) and RCM-I

459 (Fig. 11c) integrations reveal this feature, although far more confined to the eastern edge

460 of the channel. However the RCM-C integration does not show this feature of the surface

461 Cuban counter current (Fig. 11d). 

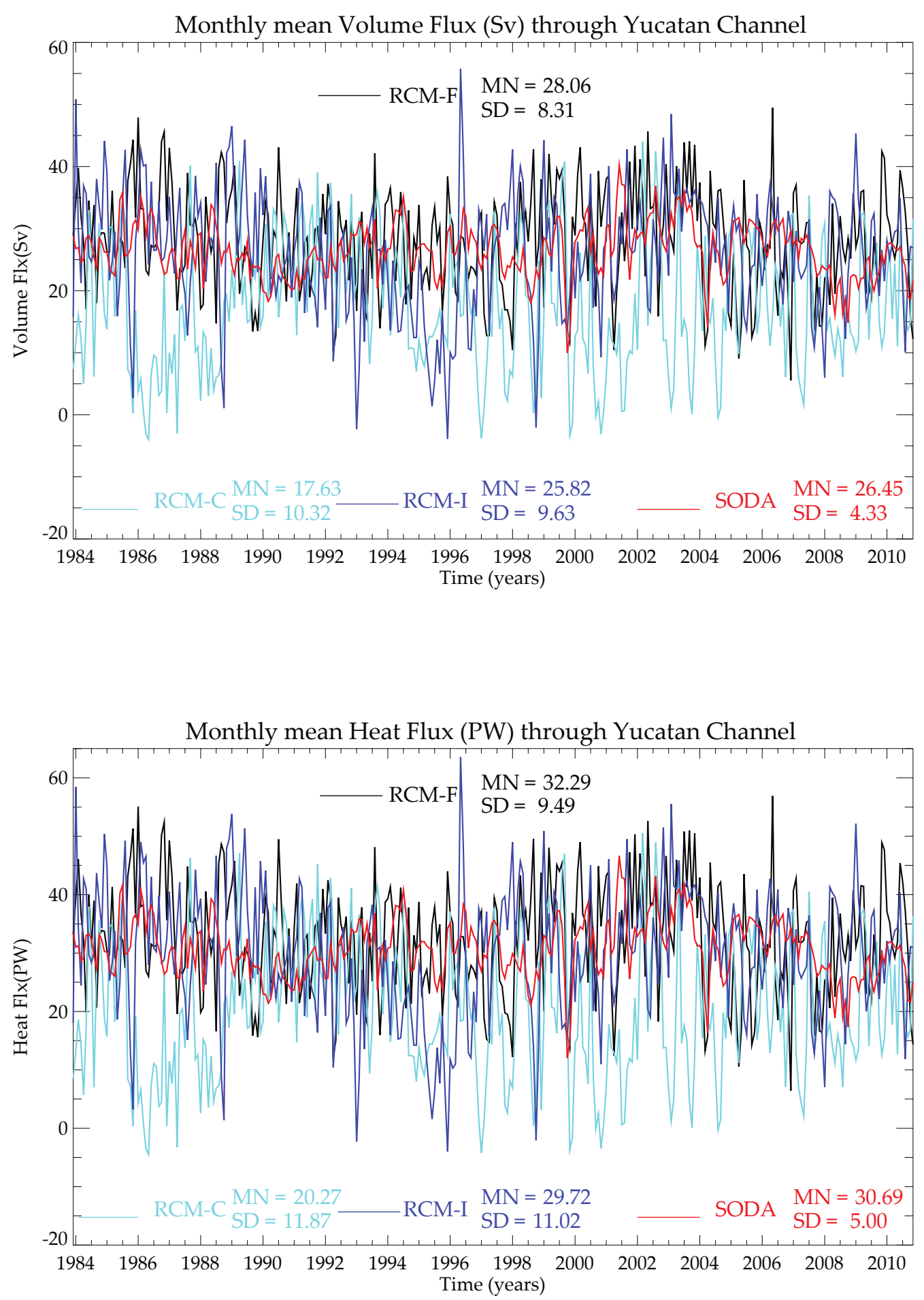

463 Figure 12: The monthly mean a) volume (in Sv) and b) heat flux (in PW) from the three 464 RCM integrations and the SODA ocean reanalysis.

465 The monthly mean volume flux and heat flux through the YC from the three RCM

466 simulations and SODA ocean reanalysis is shown in Figs. 12a and b respectively. We 
467 clearly observe from the figures that RCM-C (RCM-F) has the least (largest) volume and 468 heat fluxes through the YC, with RCM-I displaying the closest match to estimates from 469 the SODA ocean reanalysis. In comparison to the corresponding estimates from the 470 global models in Figs. 1 and 2, the bias in RCM-C (of underestimation of flow through 471 YC) resembles the corresponding bias in GFDL-ESM2G while the bias in RCM-F (of 472 overestimation) is closest to the corresponding bias in CCSM4. It should also be noted 473 that there is considerable variability in the estimates of these fluxes through YC from 474 SODA ocean reanalysis from Figs. 1 and 2 to Fig. 12, which was computed over different 475 time periods. This is not surprising given similar disparity from in situ observations of the 476 flow through the channel over different periods (Athie et al. 2015). Furthermore, it should 477 be taken into account that all three RCM simulations overestimate the standard deviation 478 of the volume and heat flux through the YC relative to SODA ocean reanalysis and the 479 global models.

480 Similarly, we also computed the annual mean climatology of the vertically 481 integrated heat transport (HT) vectors from all three RCM simulations in Fig. 13. This 482 HT is computed as:

$$
\overrightarrow{H T}=c_{p} \int_{b o t}^{\operatorname{surf}} \rho \vec{V} \theta d z------------------(1)
$$




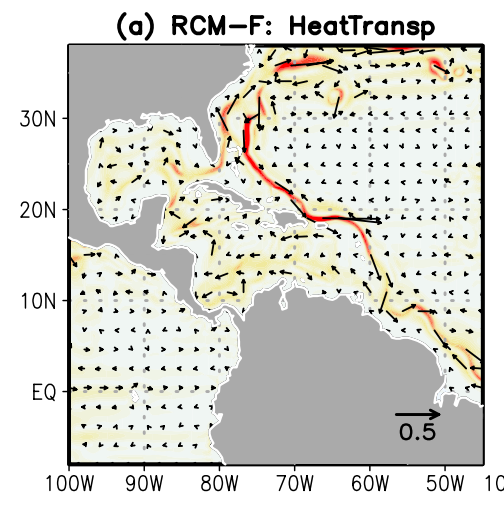

(d) (RCM-F)-SODA

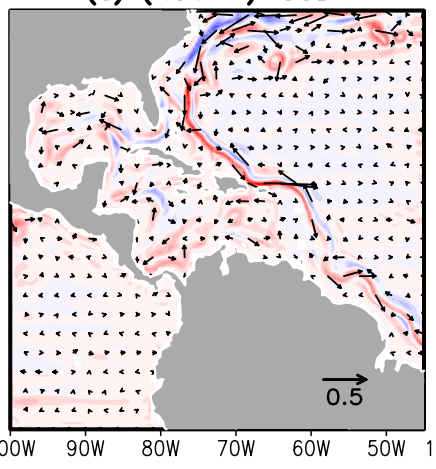

(e) (RCM-1)-SODA

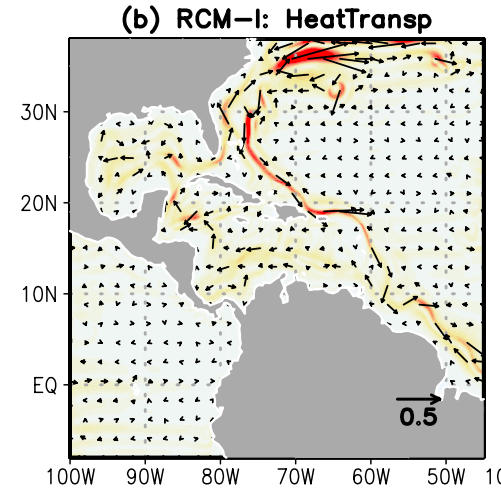

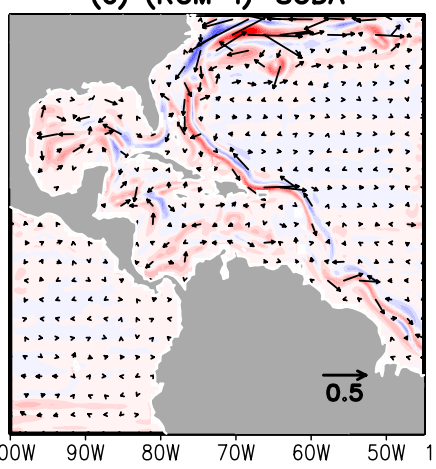

(g) $(\mathrm{RCM}-\mathrm{F})-(\mathrm{RCM}-\mathrm{I})$

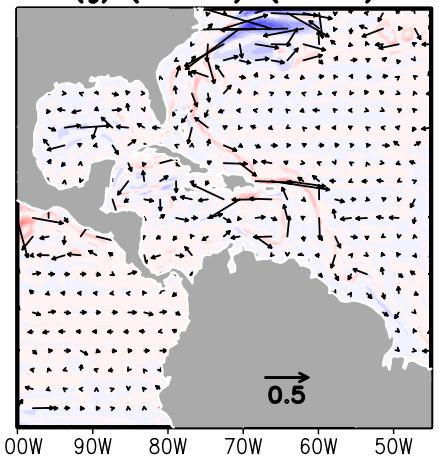

(h) $(\mathrm{RCM}-1)-(\mathrm{RCM}-\mathrm{C})$

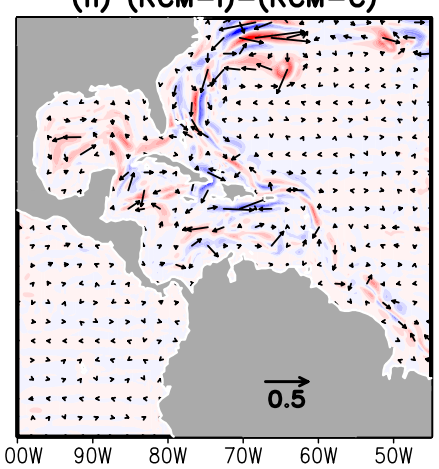

(c) RCM-C: HeatTransp

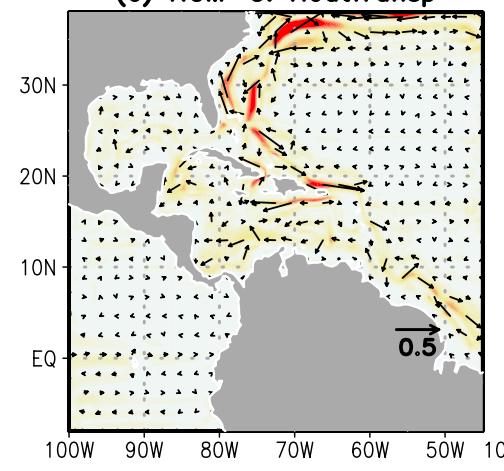

(f) $($ RCM-C)-SODA

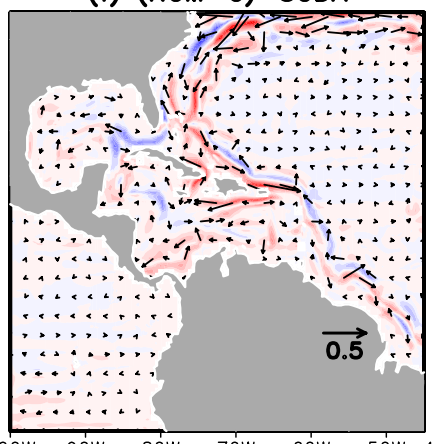

(i) $(\mathrm{RCM}-\mathrm{F})-(\mathrm{RCM}-\mathrm{C})$

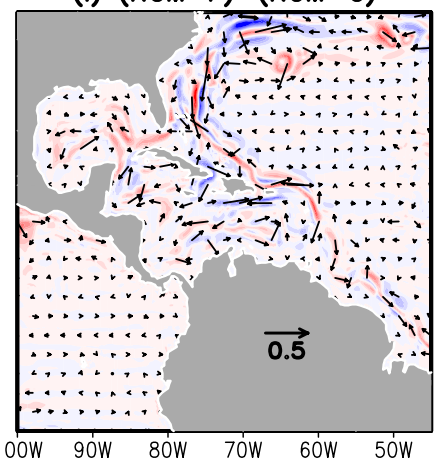

$\begin{array}{llllllllll}0 & 0.05 & 0.1 & 0.15 & 0.2 & 0.25 & 0.3 & 0.35 & 0.4 & 0.45\end{array}$

$\begin{array}{lllll}-0.5 & -0.4 & -0.3 & -0.2 & -0.1\end{array}$

$\begin{array}{lllll}0.1 & 0.2 & 0.3 & 0.4 & 0.5\end{array}$

485 Figure 13: Same as Fig. 5 but for ocean heat transport vector (equation 1). We use the 486 SODA ocean reanalysis for validation. The units are TerraWatt $[T W]\left(=1 \times 10^{12} \mathrm{~W}\right)$.

487 In Figs. 13a-c, the heat transport by the warm Caribbean Current and the Loop Current,

488 the Gulf Stream, and the return flow of the deep western boundary current is evident in 
all three RCM simulations. The heat transport by the upper ocean currents are reasonably

490 well represented in the RCM-F and RCM-I simulations. But the heat transport by the

491 return flow of the deep western boundary current is much stronger in the RCM

492 simulations than SODA ocean reanalysis (Figs. 13d-f). The heat transport by the Loop

493 Current in RCM-F and RCM-I also display a stronger northeastward tilt north of the YC

494 as compared to SODA, while the RCM-C simulation displays a very weak heat transport

495 through the YC (Fig. 13f). The differences in the heat transport in the AWP region

496 between RCM-F and RCM-I are much smaller (Fig. 13g) relative to their corresponding

497 difference from RCM-C (Figs. 13h and i). The RCM-C also has minimal heat transport

498 through the Windward and Mona passages relative to the other two RCM simulations and

499 the SODA ocean reanalysis.

$500 \quad$ e) Interannual variability

501 The contemporaneous correlation between the sea surface height and the volume 502 flux through the YC is shown in Fig. 14. In the SODA ocean reanalysis (Fig. 11a), we 503 observe that the heat content in northern Caribbean Sea around Cuba and the Bahamas

504 increases when the flow through the YC is stronger. However, stronger flow through the $505 \mathrm{YC}$ is also associated with a reduction in the heat content around the GoM coast along the

506 Florida Current, as well as the western and southern coast of the Caribbean Sea (Fig.

507 14a). These features are reasonably well captured by the RCM-I (Fig. 14c) with subtle

508 differences (e.g. over northwestern tropical Atlantic Ocean, the Caribbean coast of

509 Central America, and northern South America). On the other hand, the RCM-F

510 integration (Fig. 14b) is comparable to RCM-I but the relationship along the GoM coasts

511 and the Caribbean Sea coast along Central America and northern South America is weak 
512 and even contrary to the SODA ocean reanalysis and RCM-I. But RCM-C correlations

513 (Fig. 14d) show a far worse fidelity with respect to the SODA ocean reanalysis both in

514 the magnitude and spatial extent of the correlations.
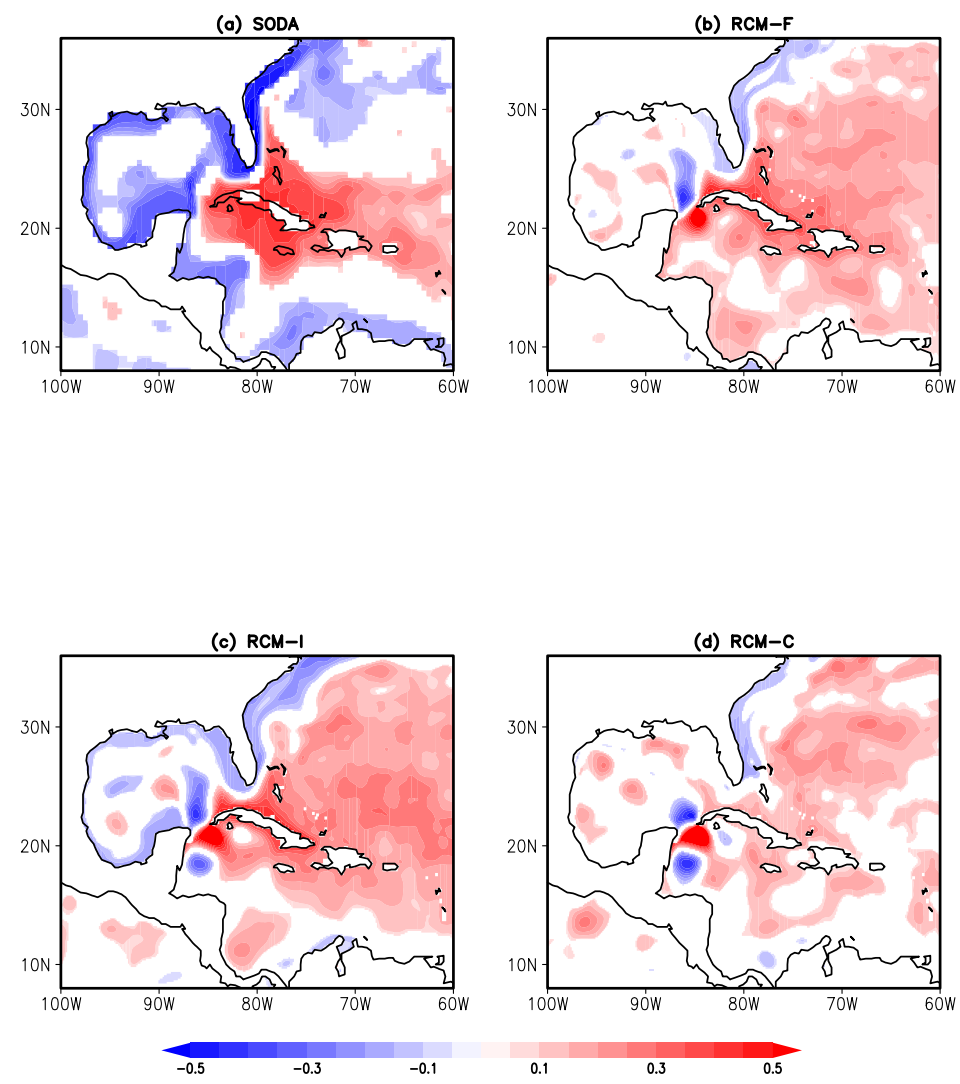

$516 \quad$ Figure 14: The contemporaneous correlations of the flow through the Yucatan Channel 517 with sea surface height anomalies from a) SODA, b) RCM-F, c) RCM-I and d) RCM-C 518 integrations. Only significant values at 10\% significance level according to t-test are 519 plotted.

520

521 In fact, the correlations displayed in Figs. 14a and $\mathrm{c}$ are similar to those obtained in Lin et

522 al. (2009), which were acquired from a model integration data over a much shorter period 
523 of time using a very high resolution $\left(1 / 6^{\circ}\right)$ ocean model. Their study showed that the

524 transport through the YC is a minimum when the Loop Current intrudes strongly into the

525 GoM. Furthermore, they suggested that variations of the sea surface height around Cuba

526 is a result of a "compensation effect" in which the variability of the flow through the YC

527 is partially compensated by the variability of the flow around Cuba (through the Old

528 Bahama Channel).

529

530

531

532 suite of CMIP5 models (GFDL-ESM2G and CCSM4) analyzed earlier to the results from

533 our RCM integrations. Although GFDL-ESM2G grossly underestimated the ocean

534 transport through the YC, the SST bias was similar to that exhibited by CCSM4, which

535 grossly overestimated the flow through the YC. It may however be noted that the severity

536 of the cold bias in GFDL-ESM2G is more acute. We obtain a similar result from the three

537 RCM integrations analyzed in this study. RCM-F overestimates the transport through the

538 YC and yet it exhibits a cold SST bias over the IAS, which is comparable to RCM-C that

539 displays a gross underestimation of the flow through the YC. Our third RCM-I

540 integration ameliorates some of this cold SST bias relative to RCM-F and RCM-C. The

541 RCM-I simulation shows the flow through the YC is closest to the observed estimates

542 (Athie et al. 2015) and the SODA ocean reanalysis as compared to the other two RCM

543 simulations (Fig. 12). 

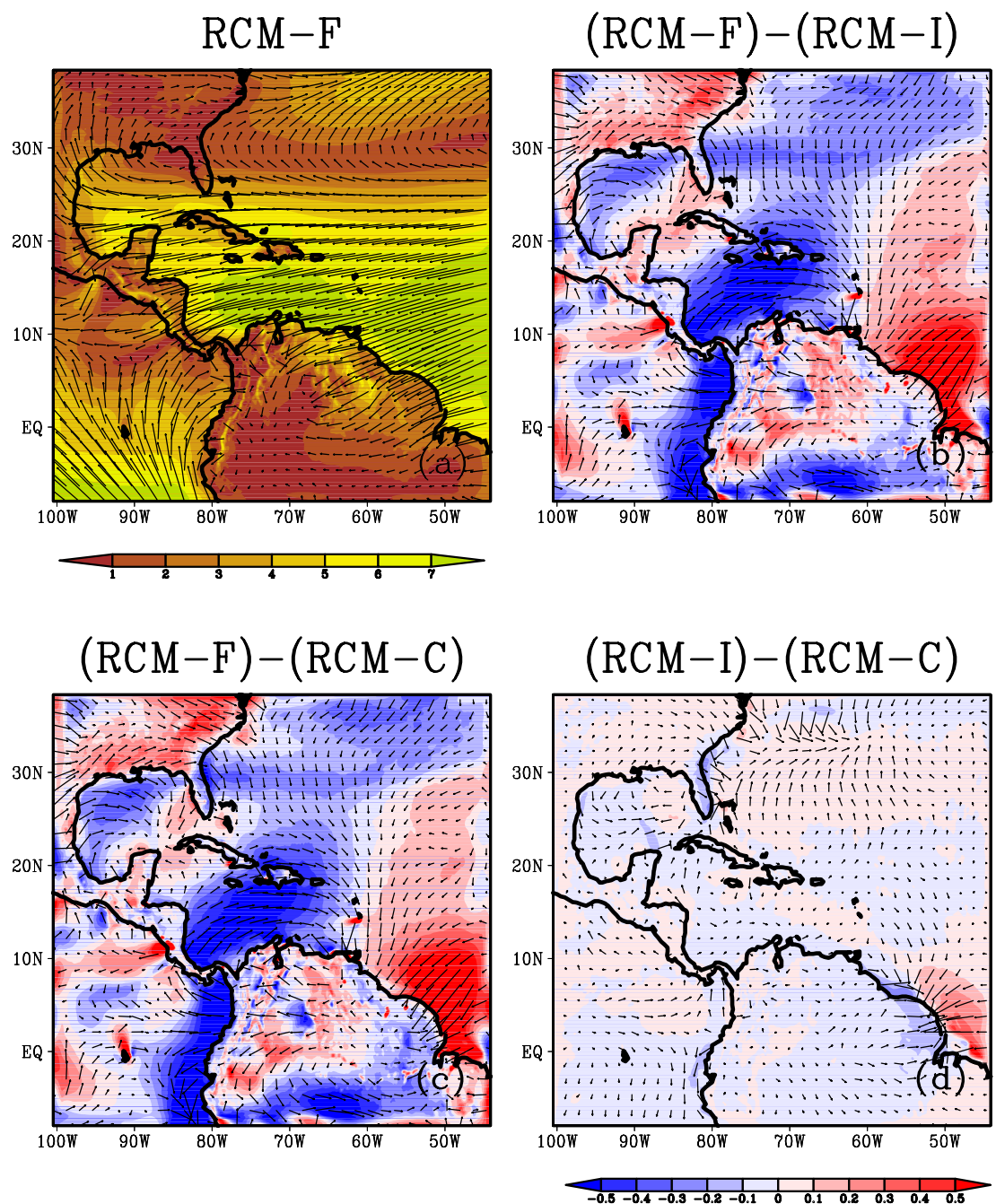

545 Figure 15: a) Annual mean climatology of the $1000 \mathrm{hPa}$ winds from RCM-F run and its 546 corresponding difference from b) RCM-I, c) RCM-C. Similarly, the climatological annual 547 mean difference of the 1000hPa winds between RCM-I and RCM-C integrations.

548 The increased flow through the $\mathrm{YC}$ has a significant impact on raising the upper ocean

549 heat content and SST in the tropical and subtropical western Atlantic Ocean (Figs. 4i, 15a

550 and b). Therefore RCM-F, which has the strongest flow through the YC, displays SST

551 warming over a considerable region across tropical-subtropical western Atlantic Ocean

552 relative to both RCM-I (Fig. 4h) and RCM-C (Fig. 4i). This is also associated with

553 considerable weakening of the atmospheric surface tropical easterlies across the IAS in

554 RCM-F (especially over the GoM and the Caribbean Sea; Fig. 15). In a related modeling 
555 study Chang and Oey (2010a) suggested that heat is transported to the western part of the

556 GoM primarily by wind-induced westward shelf currents. These currents converge in the

557 western GoM (along the TAVE and LATEX shelves) where they downwell and spread

558 heat to the interior of the ocean. As noted in Figs.14a, b, and c, the negative correlations

559 of the sea surface height variations in the Bay of Campeche and along the TAVE,

560 LATEX and Florida shelves with the transport through the YC is consistent with this

561 feature. In fact, similar correlations are also observed south of the $\mathrm{YC}$, along the eastern

562 continental shelf of Mexico in Figs. 14a and c. In RCM-C (Fig. 14d), where the flow

563 through the YC is very weak, the associated sea surface height variations along the shelf

564 in the western GoM and Caribbean Sea are weak and contrary to the SODA ocean

565 reanalysis. The absence of negative correlations in RCM-F along the TAVE and LATEX

566 shelves and along the western Caribbean coast is a result of significant weakening of the

567 shelf currents from the corresponding weakening of the atmospheric tropical easterlies.

568 This weakening of the low-level atmospheric easterlies results from the coupled air-sea

569 feedback mechanism. One of the air-sea coupled feedback mechanisms is preferentially

570 fostered in the boreal summer season by a Gill-type atmospheric response to off

571 equatorial forcing of AWP induced heating (Wang et al. 2007; Wang et al. 2008; Lee et

572 al. 2009; Wang et al. 2010). These studies clearly demonstrate that atmospheric latent

573 heating induced by the warm SSTs of the seasonal AWP induce both baroclinic and

574 barotropic responses that have a tendency to weaken the easterly Atlantic trade winds. In

575 addition, the coupled feedback of wind-induced evaporation can also affect the trade

576 winds and SST in the tropical-subtropical Atlantic (Moura and Shukla 1981; Hastenrath

577 and Greischar 1993; Chang et al. 1997). This mechanism involves changes in the 
578 atmospheric boundary layer pressure gradient induced by changes in SST (e.g. from

579 seasonal evolution or variability) affecting the overlying atmospheric surface winds

580 (Lindzen and Nigam 1987) that feeds back to SST through wind induced evaporation

581 (Chang et al. 1997). Furthermore, Tanimoto and Xie (2002) suggested cloud feedback on

582 SST that manifest in coupled feedback in the tropical and subtropical Atlantic Ocean.

583 In Fig. 16 we show the climatological cross-section of zonal heat flux (equation 2)

584 across $90^{\circ} \mathrm{W}$ following Chang and Oey (2010a) from the SODA and three RCM 585 simulations.

$$
H F=c_{p}^{\text {surf }}{ }_{\text {bot }}^{\text {und }} u d z
$$

587 where $\mathrm{u}$ is the zonal current. In the SODA ocean reanalysis heat is transported westward 588 into the western GoM both on the southern and northern shelf, while in the middle of the

589 basin heat is transported eastward as described in Chang and Oey 2010b. However, in the 590 three RCM simulations heat is transported westward only in the southern shelf while heat

591 is transported eastward in the northern shelf and in the upper ocean in middle of the 592 basin. It is also quite apparent that the eastward flow of heat to western GoM is strongest 593 in RCM-I (Fig. 16c) and least in RCM-F (Fig. 16b). Chang and Oey (2010a) indicated

594 from their idealized modeling studies that wind-induced currents along the northern and 595 southern shelves of the GoM play an important role in the westward heat redistribution, 596 which is also reaffirmed from the three RCM simulations conducted in this study. The 597 eastward heat transport in the northern shelf is part of the Gulf-scale anticyclonic gyre 598 that dominates over the shelf currents under weak wind situation (Chang and Oey 2010b).

599 Chang and Oey (2010a) further suggested that these shelf currents induce downwelling as 
600 they flow off the shelf edge after converging in the western coast, thereby transporting 601 heat eastward in the central GoM as is seen in Figs. 16a-d.

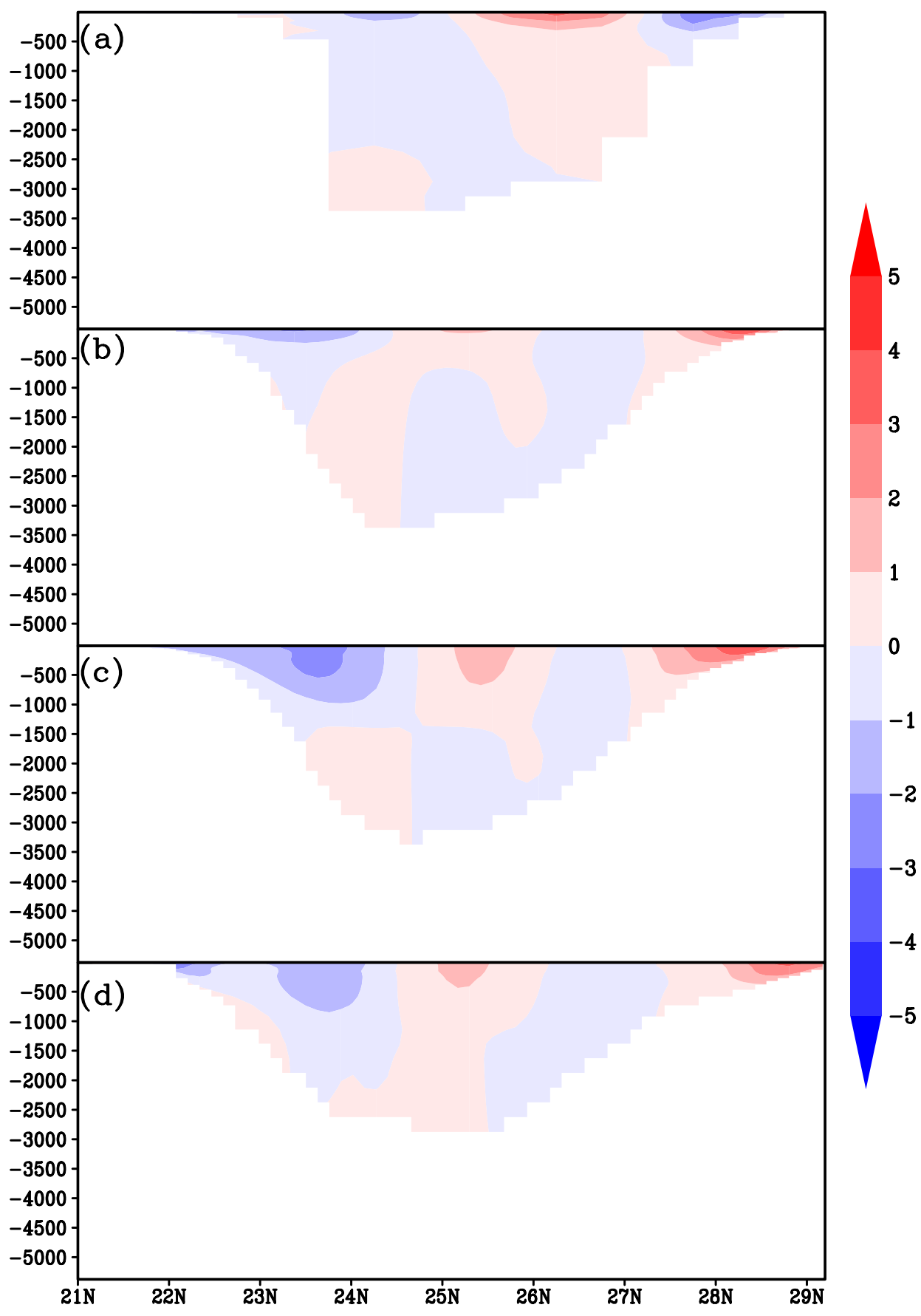

602 
603 Figure 16: Annual mean climatological heat flux across $90^{\circ} \mathrm{W}$ from a) SODA, $b$ ) $R C M-F$, 604 c) $R C M-I$, and d) $R C M-C$. The units are $\left(10^{8} \mathrm{Wm}^{-2}\right)$.

605 This study clearly shows that overcompensation of the flow through the YC (e.g.

606 in RCM-F) can result in SST bias, at least over the western GoM and even over western

607 Caribbean Sea, that resemble the SST bias from model simulations that undercompensate

608 the flow through the YC (e.g. RCM-C). Notably, 1000hPa climatological winds in the

$60920^{\text {th }}$ century simulations of CCSM4 and GFDL-ESM2G show similar differences as

610 RCM-F and RCM-C, respectively, suggesting a similar mechanism for the SST bias in

611 the western part of IAS (not shown). That said, it should also be noted that all three

612 RCM integrations display a cold SST bias in the IAS despite their varied representation

613 of the IAS ocean circulation, which would suggest that other sources of error (e.g.

614 atmospheric fluxes; remote teleconnections) are likely in play. This is further elaborated

615 by verifying the atmospheric fluxes in the simulation (Fig. 17).

616 The observed annual mean climatological atmospheric fluxes suggest that in the

617 northern parts of the AWP region there is a net upwelling atmospheric flux while in the

618 southern Caribbean Sea and southwestern GoM there is a net downwelling atmospheric

619 flux (Fig. 17a). The COREII analysis suggests that the upwelling longwave fluxes (Fig.

620 17b) and the enthalpy (sensible and latent heat) fluxes (Fig. 17d) compensate for the

621 downwelling shortwave flux (Fig. 17c) in the AWP region. The corresponding systematic

622 errors of the fluxes in RCM-F (Figs 17e-h), RCM-I (Figs. 17i-l), and RCM-C (Figs. 17m-

623 p) are comparable. Furthermore, it seen that these model simulations overestimate the

624 downwelling shortwave flux significantly, which is over compensated by the

625 overestimation of the upwelling longwave flux and enthalpy fluxes to result in a net heat

626 flux that is upwelling in the AWP region. It is interesting to note that despite the decrease 
627 in the easterly trades in RCM-F the upwelling enthalpy fluxes are still large, which stems

628 from a dry bias in the boundary layer (not shown). This dry bias increases the humidity

629 gradient between the surface and the boundary layer thereby raising the enthalpy fluxes.

630 The dry bias in the boundary layer also contributes to increased upward longwave flux as

631 well as a lower shallow cloud fraction relative to corresponding the observed cloud

632 fraction (Rossow et al. 1996; not shown), which results in higher downwelling shortwave

633 flux in all three model simulations. Furthermore, it seems clear that the bias in the net

634 heat flux from the model simulations is far larger over the open oceans than the inter-

635 model differences, which are significantly large in the coastal and over broad (shallower)

636 continental shelf regions (see Fig. 8). 

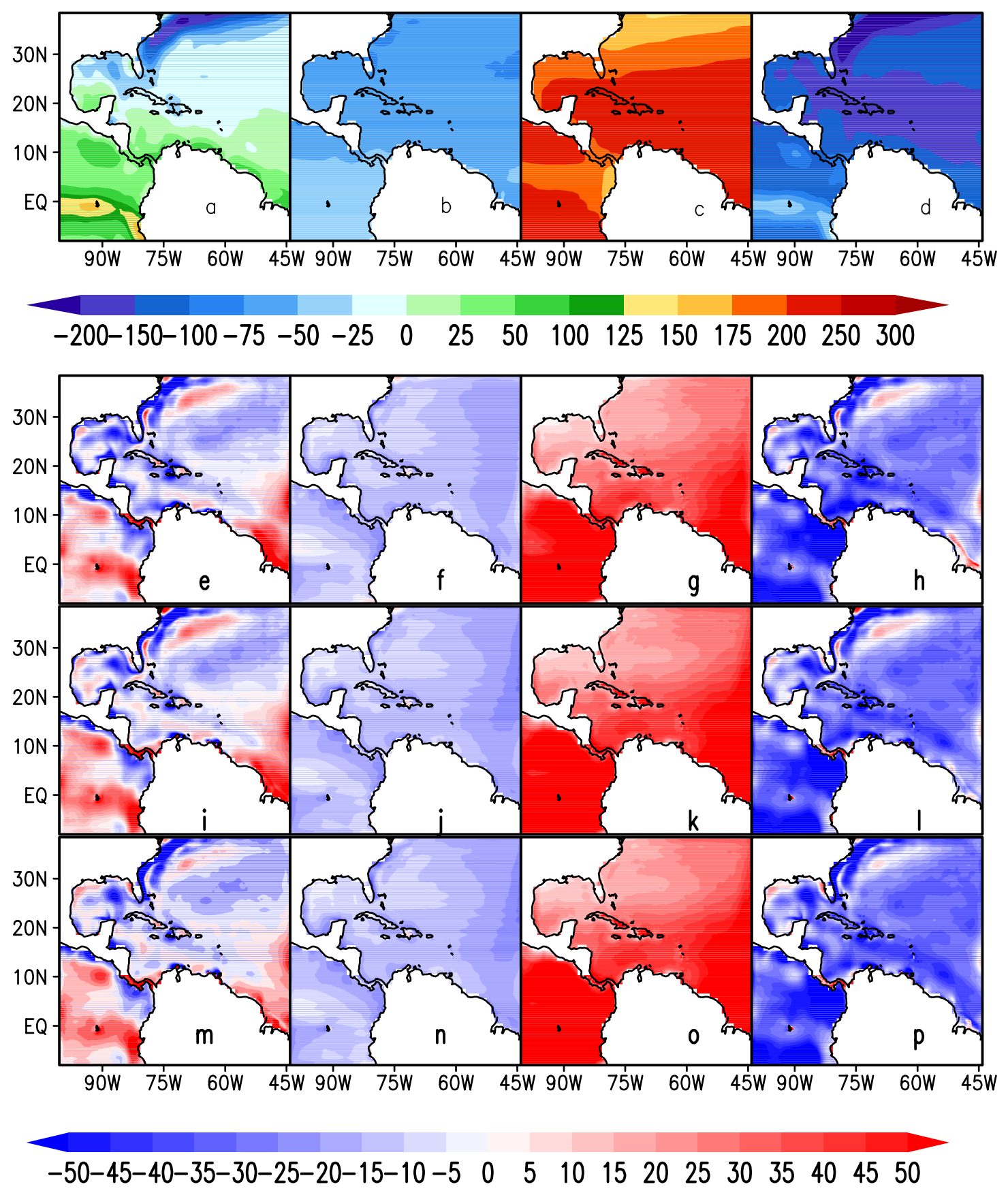

638 Figure 17: The annual mean climatological a) net heat flux, b) upwelling longwave flux, 639 c) downwelling shortwave flux, and d) enthalpy (sensible and latent) fluxes from COREII.

640 Positive (negative) sign of fluxes indicate into (out of) the ocean surface. The 641 corresponding systematic errors of the fluxes from RCM-F (e-h), RCM-I (i-l), and RCM$642 C(m-p)$. The units are in $\mathrm{Wm}^{-2}$.

643

644 7. Summary and conclusions 
In this study we conduct three multi-decadal integrations (for a duration of 32 646 years) with a relatively high resolution $(15 \mathrm{~km})$ regional coupled ocean-atmosphere

647 model (RCM) centered over the IAS. These model integrations are conducted with the

648 same numerical model at identical spatial resolution and with the same lateral boundary

649 conditions for the atmosphere and the ocean. However, the important difference in these

650 integrations is that they are prescribed uniquely different bathymetries. As a result, some

651 of the topographical features including the depth of the YC, Florida Straits, and the slope

652 of the continental shelves were different in these RCM integrations. In terrain following

653 models such as ROMS, smoothing of the bathymetry is customary to avoid large errors in

654 the computation of the horizontal pressure gradient in the presence of steep gradient in

655 bathymetry. An important part of this study is understanding the potential sources of error

656 in simulating the climate of a region such as the IAS, which displays complex bathymetry

657 and hosts a very large and very warm pool of water in part of the year that elicits strong 658 atmospheric response.

659 These model experiments highlight the importance of ocean circulation in the 660 maintenance of the heat content and SST structure in the IAS region. Our results suggest 661 that differences in bathymetry, primarily those that affect the flow through the YC, can 662 have a significant impact on the ocean circulation and temperature in the IAS region. 663 However, a sobering and a counter-intuitive result is that a more realistic bathymetry 664 does not uniformly improve the simulation over the IAS owing to other sources of model 665 errors. It is noted that all model simulations of the study systematically underestimate the 666 net heat atmospheric flux into the ocean. 
668 the underestimation of upper ocean heat content generated by the smoother bathymetry 669 over most parts of the IAS, similar to the bias displayed by majority of the general 670 circulation models. In the case of the RSM-ROMS integration with the smoother 671 bathymetry (RCM-C), we show that this surface manifestation of a colder SST is more 672 acute than in RCM-I or RCM-F over the southern limb of the Gulf Stream, followed then 673 by that over the GoM, the northern Caribbean Sea, and parts of tropical and subtropical 674 western Atlantic Ocean. There are, however, regions over the southern Caribbean Sea, 675 along the LATEX shelf, and along the northeast GoM coast where the RCM-C is warmer 676 than RCM-F.

677 As a result of the shallower depth of the $\mathrm{YC}$ in the RCM-C there is a clear 678 reduction in the mean meridional flow through the Channel. Furthermore, the Windward 679 Passage in RCM-C exhibits direction of heat transport contrary to either RCM-F or 680 SODA reanalysis. Both of these factors affect the heat transport by the Gulf Stream in the 681 RCM-C resulting in larger biases of SST and heat content in the IAS and western tropical 682 and subtropical Atlantic Ocean.

683 The flow through the YC clearly impacts the heat content locally and remotely in 684 a large section of the IAS region by affecting the heat transport by the prevailing upper 685 ocean currents in the region. But RCM-C significantly underestimates the flow through 686 the YC and RCM-F overestimates the flow through the YC. Yet, both exhibit a cold SST 687 bias that is similar to the bias displayed by GFDL-ESM2G and CCSM4 $20^{\text {th }}$ century 688 simulations over the IAS. We find that the warming of the upper ocean in the western 689 tropical and sub-tropical Atlantic Ocean in RCM-F from the increased Loop Current 
690 circulation results in significant weakening of the overlying atmospheric easterlies. This,

691 in turn, weakens the wind-induced shelf currents in the western GoM and the Caribbean

692 Sea, thus exacerbating the SST bias in RCM-F relative to RCM-I and RCM-C. Notably,

693 although alike in RCM-C and RCM-F, the cause of SST bias is quite different - the

694 former is a consequence of a weakened Loop Current while the latter results from a

695 coupled ocean-atmosphere response to a stronger Loop Current. The former (RCM-C)

696 would benefit from an improved bathymetry while the latter (RCM-F) would likely

697 improve from better coupled response of the atmosphere to SST anomalies in the IAS.

698 And all three RCM simulations would benefit from improved parameterization of the

699 atmospheric fluxes as they uniformly overestimate the downwelling shortwave flux,

700 upwelling longwave flux, and the enthalpy fluxes. In the meantime, despite its slightly

701 inferior bathymetry to RCM-F, RCM-I shows a comparatively smaller SST bias in the

702 IAS through a likely compensation of errors in the ocean and atmospheric components of 703 the RCM.

704

705 Acknowledgements

706 The authors would like to thank Ms. Tracy Ippolito of the Center for Ocean-Atmospheric

707 Studies, Florida State University for the editorial assistance. This work was supported by 708 grants from NOAA (NA12OAR4310078, NA11OAR4310110) and USGS G13AC00408.

709 The supercomputing facility provided by XSEDE under grant number ATM10010 was

710 used to complete the model integrations used in this study. 


\section{References}

713 Alpert, J.C., Kanamitsu, M., Caplan, P.M., Sela, J.G., White, G., Kalnay, E., 1988.

714 Mountain induced gravity wave drag parameterization in the NMC medium-range

715 model. Preprints, Eighth conference on Numerical Weather Prediction, American

716 Meteorological Soc., Baltimore, MD, pp. 726-733.

717 Athie, G., Sheinbaum, J., Leben, R., Ochoa, J., Shannon, M.R., Candela, J., 2015.

718 Interannual variability in the Yucatan Channel flow. Geophys. Res. Lett. 42, 1496-

719 1503, doi:10.1002/2014GL062674.

720 Bonjean, F., Lagerloef, G.S.E., 2002. Diagnostic Model and Analysis of the Surface

721 Currents in the Tropical Pacific Ocean. J. Phys. Oceanogr. 32, 2938-2954, 722 doi:http://dx.doi.org/10.1175/1520-0485(2002)032<2938:DMAAOT>2.0.CO;2.

723 Bosart, L.F., Lin, S.C., 1984. A diagnostic analysis of the Presidents' Day storm of

724 February 1979. Mon. Wea. Rev., 112, 2148-2177, 725 doi:http://dx.doi.org/10.1175/1520-0493(1984)112<2148:ADAOTP>2.0.CO;2.

726 Businger, S., Knapp, D.I., Watson, G.F., 1990. Storm Following Climatology of

727 Precipitation Associated with Winter Cyclones Originating Over the Gulf of 728 Mexico. Wea. Forecasting, 5, 378-403, doi:http://dx.doi.org/10.1175/1520$729 \quad$ 0434(1990)005<0378:SFCOPA >2.0.CO;2.

730 Candela, J., Tanahara, S., Crepon M., Barnier, B., Sheinbaum, J., 2003. Yucatan Channel 731 flow: Observations versus CLIPPER ATL6 and MERCATOR PAM models, J. 732 Geophys. Res., 108(C12), 3385-3408, doi:10.1029/2003JC001961. 
733 Carton, J.A., Giese, B.S., 2008. A reanalysis of ocean climate using simple ocean data

734 assimilation (SODA), Mon. Weather Rev., 136, 2999-3017, 735 doi:10.1175/2007MWR1978.1.

736 Chan, S., Misra, V., 2010. A diagnosis of the 1979-2005 extreme rainfall events in the 737 southeastern United States with Isentropic Moisture Tracing. Mon. Wea. Rev., 138, 738 1172-1185, doi:http://dx.doi.org/10.1175/2009MWR3083.1.

739 Chang, P., L. Ji, and H. Li, A decadal climate variation in the tropical Atlantic ocean 740 from thermodynamic air-sea interactions, Nature, 385, 516-518, 1997.

741 Chang, Y.-L., Oey, L.-Y., 2010a. Why can wind delay the shedding of Loop Current 742 Eddies? J. Phys. Oceanogr., 40 (11), 2481-2495. doi: 743 http://dx.doi.org/10.1175/2010JPO4460.1.

744 Chang, Y.-L., Oey, L.-Y., 2010b. Eddy and wind forced heat transports in the Gulf of

745 Mexico. J. Phys. Oceanogr., $40 \quad$ (12), 2727-2742, 746 doi:http://dx.doi.org/10.1175/2010JPO4474.1

747 Cherubin, L.M., Morel, Y., Chassignet, E.P., 2006. Loop current ring shedding: the 748 formation of cyclones and the effect of topography. J. Phys. Oceanogr, 36, 569-591.

749 Chérubin, L.M., Sturges, W., Chassignet, E.P., 2005. Deep flow variability in the vicinity 750 of the Yucatan Straits from a high-resolution MICOM simulation. J. Geophys. Res., $751 \quad 110$, C04009, doi:10.1029/2004JC002280.

752 Chou, M.-D., Lee, K.-T., 1996. Parameterizations for the absorption of solar radiation by 753 water vapor and ozone. J. Atmos. Sci. 53, 1203-1208, 754 doi:http://dx.doi.org/10.1175/1520-0469(1996)053<1203:PFTAOS>2.0.CO;2. 
755 Chou, M.-D., Suarez, M.J., 1994. An efficient thermal infrared radiation parameterization

756 for use in general circulation models. Technical report series on global modeling and 757 data assimilation, NASA/TM-1994-104606, 3, pp. 85.

758 Clement, A.C., Seager, R., Murtugudde, R., 2005. Why are there tropical warm pools? J.

759 Clim. 18, 5294-5311, doi: http://dx.doi.org/10.1175/JCLI3582.1.

760 Dukhovskoy, D.S., Leben, R.R., Chassignet, E.P., Hall, C., Morey, S.L., Nedbor-Gross,

761 R., 2014. Characterization of the uncertainty in the Gulf of Mexico loop current

762 description using a multi-decadal numerical simulation and altimeter observations.

763 Deep-Sea Res., Part I Oceanographic Research Papers, 100, 140-158, 764 doi:10.1016/j.dsr.2015.01.005.

765 Dunne, J.P., John, J.G., Adcroft, A.J., Griffies, S.M., Hallberg, R.W., Shevliakova, E., 766 Stouffer, R.J., Cooke, W., Dunne, K.A., Harrison, M.J., Krasting, J.P., Malyshev, 767 S.L., Milly, P.C.D., Phillipps, P.J., Sentman, L.T., Samuels, B.L., Spelman, M.J., 768 Winton, M., Wittenberg, A.T., Zadeh, N., 2012. GFDL's ESM2 Global Coupled 769 Climate-Carbon Earth System Models. Part I: Physical Formulation and Baseline

770 Simulation Characteristics. J. Climate, 25, 6646-6665, doi: 771 http://dx.doi.org/10.1175/JCLI-D-11-00560.1.

772 Ek, M.B., Mitchell, K.E., Lin, Y., Rogers, E., Grunmann, P., Koren, V., Gayno, G., 773 Tarpley, J.D., 2003. Implementation of Noah land surface model advances in the 774 National Centers for Environmental Prediction operational mesoscale Eta model, $J$. 775 Geophys. Res., 108 (D22), 8851-8866, doi:10.1029/2002JD003296.

776 Gent, P.R., Danabasoglu, G., Donner, L.J., Holland, M.M., Hunke, E.C., Jayne, S.R., 777 Lawrence, D.M., Neale, R.B., Rasch, P.J., Vertenstein, M., Worley, P.H., Yang, Z.- 
778 L., Zhang, M., 2011. The Community Climate System Model Version 4. J. 779 Climate, 24, 4973-4991, doi:http://dx.doi.org/10.1175/2011JCLI4083.1.

780 Giese, B.S., Ray, S., 2011. El Niño variability in Simple Ocean Data Assimilation 781 (SODA), 1871-2008, J. Geophys. Res., 116, C02024, doi:10.1029/2010JC006695.

782 Haidvogel, D.B., Arango H.G., Hedstrom K., Beckmann A., Malanotte-Rizzoli P., 783 Shchepetkin A.F., 2000. Model evaluation experiments in the North Atlantic Basin: 784 simulations in nonlinear terrain-following coordinates. Dyn Atmos Oceans 32: 239785 281, doi:10.1016/S0377-0265(00)00049-X.

786 Haney, R.L., 1991: On the pressure gradient force over steep topography in sigma 787 coordinate ocean models. J. Phys. Oceanogr, 21, 610-619, doi: $788 \quad$ http://dx.doi.org/10.1175/1520-0485(1991)021<0610:OTPGFO>2.0.CO;2.

789 Hastenrath, S., and L. Greischar, 1993. Further work on the prediction of northeast Brazil 790 rainfall anomalies, J. Clim., 6, 743-758.

791 Helber, R.W., Weisberg, R.H., Bonjean, F., Johnson, E.S., Lagerloef, G.S.E., 2007.

792 Satellite-Derived Surface Current Divergence in Relation to Tropical Atlantic SST 793 and Wind. J. Phys. Oceanogr., 37, 1357-1375, 794 doi:http://dx.doi.org/10.1175/JPO3052.1.

795 Hong, S.Y., Pan, H.L., 1996. Nonlocal boundary layer vertical diffusion in a medium796 range forecast model. Mon Weather Rev 124, 2322-2339, doi: 797 http://dx.doi.org/10.1175/1520-0493(1996)124<2322:NBLVDI>2.0.CO;2.

798 Hurlburt, H.E., Thompson, J.D., 1980. A numerical study of Loop Current intrusions and 799 eddy shedding. J. Phys. Oceanography, 10, 1611-1651, 800 doi:http://dx.doi.org/10.1175/1520-0485(1980)010<1611:ANSOLC>2.0.CO;2. 
801 Jackett, D.R., McDougall, T.J., Feistel, R., Wright, D.G., Griffies, S.M., 2006.

802 Algorithms for Density, Potential Temperature, Conservative Temperature, and the

803 Freezing Temperature of Seawater. J. Atmos. Oceanic Technol., 23, 1709-1728, doi:

$804 \quad$ http://dx.doi.org/10.1175/JTECH1946.1.

805 Jayne, S.R., Marotzke, J., 2002. The oceanic eddy heat transport. J. Phys. Oceaongr., 32, $806 \quad 3328-3345$.

807 Juang, H.-M.H., Kanamitsu, M., 1994. The NMC nested regional spectral Model. Mon $808 \quad$ Wea Rev 122, 3-26, doi: http://dx.doi.org/10.1175/1520$809 \quad$ 0493(1994)122<0003:TNNRSM>2.0.CO;2.

810 Kanamitsu, M., Ebisuzaki, W., Wollen, J., Yang, S.-K., Hnilo, J.J., Fiorino, M., Potter, 811 G.L., 2002. NCEP-DOE AMIP-II Reanalysis. Bull. Amer. Met. Soc. 83, 1631-1643, 812 doi:http://dx.doi.org/10.1175/BAMS-83-11-1631.

813 Kanamitsu, M., Yoshimura, K., Yhang, Y.-B., Hong, S.-Y., 2010. Errors of Interannual 814 variability and Multi-Decadal Trend in Dynamical Regional Climate Downscaling 815 and its Corrections. J. Geophys. Res. 115, D17115, doi:10.1029/2009JD013511.

816 Kozar, M., Misra, V., 2012. Evaluation of Twentieth-Century Atlantic Warm Pool 817 Simulations in Historical CMIP5 Runs. Clim. Dyn., 41(9-10), 2375-2391, 818 doi:10.1007/s00382-012-1604-9.

819 Large, W.G., McWilliams, J.C., Doney, S.C., 1994. Oceanic vertical mixing: A review 820 and a model with a nonlocal boundary layer parameterization, Rev. Geophys., 32, $821 \quad$ 363-403, doi:10.1029/94RG01872.

822 Large, W.G., Yeager, S.G., 2009. The global climatology of an internationally varying 823 air-sea flux data set. Clim Dyn 33, 341-364, doi:10.1007/s00382-008-0441-3.Leben, 
824 R.R., 2005. Altimeter-derived loop current metrics. In: Sturges, W., Lugo-Fernandez

825 (Eds.):Circulation in Gulf of Mexico: Observations and models, Geophysical

826 Monograph Series, American Geophysical Union, Volume 161, pp. 181-201,

827 doi:10.1029/161GM15.

828 Lee, S.-K., Enfield, D.B., Wang, C., 2005. Ocean general circulation model sensitivity

829 experiments on the annual cycle of Western Hemisphere Warm Pool. J. Geophys.

$830 \quad$ Res. 110, C09004, doi:10.1029/2004JC002640.

831 Lee, S.-K., Enfield, D.B., Wang, C., 2007. What Drives Seasonal Onset and Decay of the

832 Western Hemisphere Warm Pool? J. Clim., 20, 2133-2146, doi:

$833 \quad$ http://dx.doi.org/10.1175/JCLI4113.1.

834 Lee, S.-K., C. Wang, and B.E. Mapes, 2009. A simple atmospheric model of the local

835 and teleconnection responses to tropical heating anomalies. Journal of Climate, $83622(2): 227-284$.

837 Li, H., Kanamitsu, M., Hong, S.-Y., 2012. California reanalysis downscaling at $10 \mathrm{~km}$

838 using an ocean-atmosphere coupled regional model system. J. Geophys. Res.

839 (Atmospheres), 117, D12118, doi:10.1029/2011JD017372.

840 Li, H., Kanamitsu, M., Hong, S.-Y., Yoshimura, K., Cayan, D.R., Misra, V., Sun, L.,

841 2014. Projected climate change scenario over California by a regional ocean-

842 atmosphere coupled model system. Climatic Change, 122(4), 609-619, 843 doi:10.1007/s10584-013-1025-8.

844 Li, H., Kanamitsu, M., Hong, S.-Y., Yoshimura, K., Cayan, D.R., Misra, 2013. A high845 resolution ocean-atmosphere coupled downscaling of the present climate over 846 California. Clim. Dyn., doi:10.1007/s00382-013-1670-7. 
847 Li, H., Misra, V., 2014. Thirty-two year ocean-atmosphere coupled downscaling of 848 global reanalysis over the Intra-American Seas. Clim. Dyn., 43(9), 2471-2489, 849 doi:10.1007/s00382-014-2069-9.

850 Lin, Y., Greatbatch, R.J., Sheng, J., 2009. A model study of the vertically integrated 851 transport variability through the Yucatan Channel: Role of Loop Current Evolution 852 and flow compensation around Cuba. J. Geophys. Res., 114, C08003, 853 doi:10.1029/2008JC005199.

854 Lindzen, R. S. and S. Nigam, 1987: On the role of sea surface temperature gradients in 855 forcing low-level winds and convergence in the tropics. J. Atmos. Sci., 44, 24188562436.

857 Liu, H., Wang, C., Lee, S.-K., Enfield, D.B., 2012a. Atlantic warm pool variability in the 858 IPCC AR4 CGCM simulations. J. Climate, 25, 5612-5628, doi: 859 http://dx.doi.org/10.1175/JCLI-D-11-00376.1.

860 Liu, H., Wang, C., Lee, S.-K., Enfield, D.B., 2013. Atlantic warm pool variability in the 861 CMIP5 simulations. J. Climate, 26, 5315-5336, doi:http://dx.doi.org/10.1175/JCLI$862 \quad$ D-12-00556.1.

863 Liu, Y., Lee, S.-K., Enfield, D.B, Muhling, B.A., Lamkin, J.T., Muller-Karger, F., Roffer, 864 M.A., 2015. Potential impact of climate change on the Intra-Americas Seas: Part-1. A 865 dynamic downscaling of the CMIP5 model projections. J. Marine Syst., 148, 56-69, 866 doi:10.1016/j.jmarsys.2015.01.007.

867 Liu, Y., Lee, S.-K., Muhling, B.A., Lamkin, J.T., Enfield, D.B., 2012b. Significant 868 reduction of the Loop Current in the 21st century and its impact on the Gulf of 869 Mexico. J. Geophys. Res., 117, C05039, doi:10.1029/2011JC007555. 
870 Locarnini, R. A., Mishonov, A.V., Antonov, J.I., Boyer, T.P., Garcia, H.E., Baranova, 871 O.K., Zweng, M.M., Paver, C.R., Reagan, J.R., Johnson, D.R., Hamilton, M., 872 Seidov, D., 2013. World Ocean Atlas 2013, Volume 1: Temperature. S. Levitus, S., 873 (Ed.), Mishonov, A., (Technical Ed.); NOAA Atlas NESDIS 73, pp. 40.

874 Mainelli, M., DeMaria, M., Shay, L.K., Goni, G., 2008. Application of oceanic heat 875 content estimation to operational forecasting of recent Atlantic category 5 hurricanes. 876 Wea. Forecasting, 23(1), 3-16, doi:http://dx.doi.org/10.1175/2007WAF2006111.1.

877 Martinho, A.S., Batteen, M.L., 2006. On reducing the slope parameter in terrain 878 following numerical ocean models. Ocean Modell., 13(2), 166-175, 879 doi:10.1016/j.ocemod.2006.01.003.

880 Mellor, G.L., Ezer, T., Oey, L.-Y., 1994. The pressure gradient conundrum of sigma 881 coordinate ocean models. J. Atmos. Ocean Tech., 11(4), 1126-1134, doi: 882 http://dx.doi.org/10.1175/1520-0426(1994)011<1126:TPGCOS>2.0.CO;2.

883 Mellor, G.L., Yamada, T., 1982. Development of a turbulence closure model for 884 geophysical fluid problems, Rev. Geophys., 20, 851-875, 885 doi:10.1029/RG020i004p00851.

886 Misra, V., Chan, S., Wu, R., Chassignet, E., 2009. Air-sea interaction over the Atlantic 887 warm pool in the NCEP CFS. Geophys. Res. Lett., 36, L15702, 888 doi:10.1029/2009GL038525.

889 Misra, V. and A. Mishra, 2016: The oceanic influence on the rainy season of Peninsular 890 Florida. J. Geophys. Res. (Atmospheres), doi:10.1002/2016JD024824. In press. 
891 Misra, V., Li, H., Kozar, M., 2014. The precursors in the Intra-Americas Seas to seasonal

892 climate variations over North America. J. Geophys. Res. (Oceans), 119 (5), 2938-

893 2948, doi:10.1002/2014JC009911.

894 Misra, V., Stroman, A., DiNapoli, S., 2013. The rendition of the Atlantic Warm Pool in 895 the reanalyses. Clim. Dyn., 41, 517-532, doi:10.1007/s00382-012-1474-1.

896 Mo, K.C., Chelliah, M., Carrera, M., Higgins, R.W., Ebisuzaki,W., 2005. Atmospheric 897 moisture transport over the United States and Mexico as evaluated in the NCEP 898 regional reanalysis. J. Hydromet, 6, 710-728.

899 Moorthi, S., Suarez, M.J., 1992. Relaxed Arakawa-Schubert. A parameterization of moist 900 convection for general circulation models. Mon. Wea. Rev. 120, 978-1002, doi: $901 \quad$ http://dx.doi.org/10.1175/1520-0493(1992)120<0978:RASAPO>2.0.CO;2.

902 Moura, A. D. and Shukla, J. 1981. On the dynamics of droughts in northeast Brazil: 903 observations, theory and numerical experiments with a general circulation model. J. $904 \quad$ Atmos. Sci 38, 3653-2675.

905 Rappaport, E.N., Franklin, J.L., Schumacher, A.B., DeMaria, M., Shay, L.K., Gibney, 906 E.J., 2010. Tropical intensity change before U. S. Gulf coast landfall. Wea. $907 \quad$ Forecasting, 25, 1380-1396, doi:10.1175/2010WAF2222369.1.

908 Reynolds, R.W., Smith, T.M., Liu, C., Chelton, D.B., Casey, K.S., Schlax, M.G., 2007.

909 Daily High-Resolution-Blended Analyses for sea surface temperature. J Climate 20, 910 5473-5496, doi:http://dx.doi.org/10.1175/2007JCLI1824.1.

911 Rossow, W. B., Walker A. W., Beuschel D. E., Roiter M. D., 1996. International Satellite 912 Cloud Climatology Project (ISCCP) Documentation of new cloud datasets. 913 WMO/TD-No. 737, World Meteorological Organization, 115 pp 
914 Ruiz-Barradas, A., Nigam, S., 2005. Warm season rainfall variability over the US great 915 plains in observations, NCEP and ERA-40 Reanalyses, and NCAR and NASA 916 Atmospheric Model Simulations, J. Climate, 18(11), 1808-1830, doi: 917 http://dx.doi.org/10.1175/JCLI3343.1.

918 Schmitz, W.J., Richardson, P.L., 1991. On the sources of the Florida Current. Deep Sea

919 Res., Part A, 38, S379 - S409, doi:10.1016/S0198-0149(12)80018-5.

920 Shay, L.K., 2009. Upper ocean structure: Response to strong forcing events.

921 Encyclopedia of Ocean Sciences. 2nd ed. J. Steele et al., (Eds.), Elsevier, 192-210, 922 doi:10.1016/B978-012374473-9.00628-7.

923 Shay, L.K., Goni, G.J., Black, P.G., 2000. Effects of a warm oceanic feature on

924 Hurricane Opal. Mon. Wea. Rev., 128(5), 1366-1383, 925 doi:http://dx.doi.org/10.1175/1520-0493(2000)128<1366:EOAWOF>2.0.CO;2.

926 Shchepetkin, A.F., McWilliams, J.C., 2005. The Regional Oceanic Modeling System 927 (ROMS): A split-explicit, free-surface, topography-following-coordinate ocean 928 model. Ocean Modell., 9, 347-404.

929 Sheinbaum, J., Candela, J., Badan, A., Ochoa, J., 2002. Flow structure and transport 930 through the Yucatan Channel. Geophys. Res. Lett., 29(3), 1040, 931 doi:10.1029/2001GL013990.

932 Sikiric, M.D., Janekovic, I., Kuzmic, M., 2009. A new approach to bathymetry 933 smoothing in sigma-coordinate ocean models. Ocean Modell., 29(2), 128-136, 934 doi:10.1016/j.ocemod.2009.03.009. 
935 Tanimoto, Y., and S.-P. Xie, Inter-hemispheric decadal variations in SST, surface wind, 936 heat flux and cloud cover over the Atlantic Ocean, J. Meteorol. Soc. Jpn., 80, 1199$937 \quad 1219,2002$.

938 Tiedtke, M., 1983. The sensitivity of the time-mean large-scale flow to cumulus 939 convection in the ECMWF model. In: Proceedings of ECMWF workshop on 940 convective in large-scale models, Reading, United Kingdom, European Centre for 941 Medium-Range Weather Forecasts, pp. 297-316

942 Umlauf, L., Burchard, H., 2003. A generic length-scale equation for geophysical 943 turbulence models. J. Mar. Res., 61(2), 235-265, doi:10.1357/002224003322005087.

944 Wang, C., and D. B. Enfield, 2001. The tropical Western Hemisphere warm 945 pool. Geophys. Res. Lett., 28, 1635-1638.

946 Wang, C., Enfield, D.B., 2003. A further study of the tropical Western Hemisphere

947 Warm Pool. J. Climate, 16(10), 1476-1493, doi:http://dx.doi.org/10.1175/1520-0442$948 \quad 16.10 .1476$.

949 Wang, C., Enfield, D.B., Lee, S.-K., Landsea, C., 2006. Influences of the Atlantic warm 950 pool on Western Hemisphere summer rainfall and Atlantic hurricanes. J. Climate, 951 19(12), 3011-3028, doi:http://dx.doi.org/10.1175/JCLI3770.1.

952 Wang, C., S.-K. Lee, and D. B. Enfield, 2007. Impact of the Atlantic warm pool on the 953 summer climate of the Western Hemisphere. J. Climate, 20, 5021-5040.

954 Wang, C., Lee, S.-K., Enfield, D.B., 2008a. Climate response to anomalously large and 955 small Atlantic Warm pools during the summer. J. Climate, 21(11), 2437-2450, doi: $956 \quad$ http://dx.doi.org/10.1175/2007JCLI2029.1. 
957 Wang, C., Lee, S.-K., Enfield, D.B., 2008b. Atlantic Warm Pool Acting as a Link 958 between Atlantic Multidecadal Oscillation and Atlantic Tropical Cyclone Activity. 959 Geochem. Geophys. Geosyst., 9(5), Q05V03, doi:10.1029/2007GC001809.

960 Zhang, L., Wang, C., Xiu, L., 2012. Low frequency modulation of the Atlantic warm 961 pool by the Atlantic multidecadal oscillation. Clim. Dyn., 39(7), 1661-1671, 962 doi:10.1007/s00382-011-1257-0.

963 